\title{
Warm Spray Forming of Ti-6Al-4V
}

R.M. Molak, H. Araki, M. Watanabe, H. Katanoda, N. Ohno, and S. Kuroda

(Submitted May 9, 2013; in revised form October 1, 2013)

\begin{abstract}
Warm spray (WS) is a modification of high-velocity oxy-fuel spraying, in which the temperature of the supersonic gas flow generated by the combustion of kerosene and oxygen is controlled by diluting the combustion flame with an inert gas such as nitrogen. The inert gas is injected into the mixing chamber placed between the combustion chamber and the powder feed ports, thus the temperature of the propellant gas can be controlled from $\sim 700$ to $2,000 \mathrm{~K}$. Since WS allows for higher particle temperatures in comparison to cold spray, warm sprayed particles are more softened upon impact, thus resulting in greater deformation facilitating the formation of shear instability for bonding. Recently, the combustion pressure of WS has been increased from 1 (low-pressure warm spray) to 4 MPa (high-pressure warm spray) in order to increase the velocity of sprayed particles. Effects of spray parameters on microstructure, mechanical properties, and splats formation of Ti-6Al-4V were systematically studied. Obtained coatings were examined by analyzing the coating cross-section images, microhardness as well as oxygen content. In addition, flattening ratio of splats was calculated as a function of nitrogen flow rate. It was found that the increased particle velocity caused by the increased combustion pressure had significant beneficial effects in terms of improving density and controlling the oxygen level in the sprayed Ti-6Al-4V coatings.
\end{abstract}

Keywords microstructure, oxygen content, porosity, warm spraying

\section{Introduction}

Due to having high strength at low to moderate temperatures, light weight, and excellent corrosion resistance, titanium, and its alloys have been frequently selected to be used in a wide and diversified range of applications such as in the aerospace, automotive, power generation, oil, and gas extractions, sport industries, as well as in the biomedical field. For these applications the titanium alloys replaced heavier, less serviceable or less cost-effective materials. Ti-6Al-4V is the most widely used titanium alloy because of features like good machinability and excellent mechanical properties (Ref 1$)$.

Because of the relatively high price of titanium and difficulty in casting and welding due to its high reactivity with oxygen at high temperatures, there is a demand to develop

This article is an invited paper selected from presentations at the 2013 International Thermal Spray Conference, held May 13-15, 2013, in Busan, South Korea, and has been expanded from the original presentation.

R.M. Molak, National Institute for Materials Science (NIMS), Tsukuba, Japan, and Warsaw University of Technology, Faculty of Materials Science and Engineering, Warsaw, Poland; H. Araki, M. Watanabe, and S. Kuroda, National Institute for Materials Science (NIMS), Tsukuba, Japan; H. Katanoda, Kagoshima University, Korimoto, Kagoshima, Japan; and N. Ohno, Plasma Giken Co., Ltd., Toda, Saitama, Japan. Contact e-mails: molak.rafalmaksymilian@nims.go.jp and rmolak@inmat. pw.edu.pl. new, low-cost methods for direct fabrication of metal parts in near-net shapes (NNS) (Ref 2). For example, in aerospace industry, one important indicator of material waste is the buy to fly ratio, which is the mass of material that is need to machine a part compared to the mass of material in finished component. For compressor and ring sections, the ratio is $\sim 12: 1$ and based on an analysis performed by Pratt and Whitney, the ratio could be reduced by $41 \%$ to $7: 1$ by using cold spray (CS) for parts manufacturing (Ref 3 ).

Another important application of thermal spray process is repair of damaged parts, especially for large, complex aerospace, and aircraft components usually made of sophisticated and also expensive alloys. Although many welding processes have been developed, these may induce undesirable thermal stresses that can result in premature failure of repaired parts. Therefore, there is great interest in thermal spray technology for both production and repair of titanium alloy components. Nowadays, some thermal spray methods are considered for these applications but each of them has both strengths and weaknesses and should be chosen carefully.

In high-velocity oxy-fuel (HVOF) (Ref 4, 5), temperature range of impact particles is around 1500 to $2500 \mathrm{~K}$ and thermal degradation of the materials takes place. This process is particularly undesirable especially in the case of titanium coatings because of the high oxygen affinity of titanium and the high solid solubility of oxygen into titanium (about 14.5\%) (Ref 1). Oxidation is critical for the titanium coatings because of the possibility to form a continuous layer of oxygen stabilized $\alpha$-phase called $\alpha$-case. The hard and less ductile $\alpha$-case can lead to a significant loss of plasticity. For highly reactive materials such as titanium, solid state processing is attractive because it can reduce the rate of oxidation during in-flight of the powder particles.

One thermal spray technique which allows to suppress the oxidation problem is low-pressure plasma spray 
(LPPS) (Ref 6, 7). In LPPS the problem of oxidation is overcome or minimized by enclosing the entire plasma spraying unit in an evacuated chamber, which is maintained at about 20 to 100 Torr inert gas pressure. Therefore LPPS needs a large vacuum chamber, which inevitably makes the equipment cost high. The other disadvantage is that coatings often exhibit non-equilibrium microstructure due to rapid quenching of the order $10^{5}$ to $10^{6} \mathrm{~K} / \mathrm{s}$.

Another relatively new method explored today is CS (Ref 8-10). In CS a supersonic jet of compressed inert gas expands through a DeLaval type nozzle and accelerates particles to velocity in the range of 300 to $1200 \mathrm{~m} / \mathrm{s}$. For high-strength materials such as Ti-6Al-4V, however, it is difficult to form a dense coating because of the high velocity required to form bonding between particles. Only if the impact conditions meets a certain criterion such as particle velocity exceeding a critical value (Ref 11,12$)$, the phenomenon called adiabatic shear instability appear, which is caused by dominance of thermal softening over work hardening in the interfacial region of sprayed particle and the substrate. This can lead to local softening or partial melting of the materials (Ref 10, 11, 13).

There are two ways to achieve sufficient bonding between powder particles, improve deposition efficiency and reduce porosity in thus formed deposits. The first one is to use helium as the propellant gas for accelerating the alloy particles to sufficiently high velocity (Ref $3,14,15)$. Because of the high cost of helium, however, it requires a gas recycling facility, which requires a large initial investment. The second one way is preheating the powder before impacts with the substrate (Ref 3). Notwithstanding, the problem is that CS has a difficulty in increasing the temperature of impact particle above $1200 \mathrm{~K}$ due to the technical and design requirements for materials used for manufacturing of a thermal spray gun.

CS technique was successfully used for repair of magnesium transmission and gearbox housings for a rotorcraft damaged by corrosion as well as repair of aluminum mold surface damaged due to thermal fatigue (Ref 16, 17). In contrast to repair by commonly used welding, CS does not introduce thermal residual stress, which shorten the lifecycle of restored molds. In short, there is possibility to use CS for repair components made of easily sprayable materials but there are some restrictions for higher yield strength materials due to the limitations in CS process temperature.

Another technique which allows higher temperature of deposited particles in contrast to CS is warm spray (WS). The method was developed by modifying a conventional HVOF system, in which the gas temperature can be controlled between HVOF and CS (700 to 1900 K) (Ref 17-19). In WS the temperature of a supersonic gas flow generated by the combustion of kerosene and oxygen is controlled by diluting the combustion flame with an inert gas such as nitrogen. The inert gas is injected into the mixing chamber (MC) placed between the combustion chamber (CC) and the powder feed ports. Thus, the process can generate a flux of powder particles with well-controlled temperature and velocity. By its higher particle temperature in comparison to $\mathrm{CS}$, warm-sprayed particles are more softened upon impact, thus resulting in greater deformation facilitating the occurrence of adiabatic shear instability for bonding. The main advantage of WS is that many powder materials can be deposited in thermally softened state at high impact velocity, which allows to form dense coatings of materials such as Ti (Ref 17, 20-22), Cu (Ref 22), Al (Ref 22), and WC-Co (Ref 23, 24) with controlled oxidation.

Since Ti-6Al-4V retains its high yield strength even in high temperatures up to $700 \mathrm{~K}$ (Ref 25), it is difficult to produce dense coating. There have been several efforts to produce Ti-6Al-4V coatings using CS (Ref 3, 26, 27). Depending on the applied conditions and powder morphology, obtained porosity was in the range from about 2.5 (Ref 3) to 22 vol. \% ( Ref 26) in the as-sprayed conditions.

In some recent papers on titanium coatings formed by WS (Ref 21, 22), it has been indicated that microstructure and mechanical properties of sprayed coatings significantly depend on the nitrogen flow rates and thus particle temperature. For example, Kim et al. (Ref 21) reported that when the nitrogen flow rate increases, the oxides on the particle's surface were almost eliminated, but on the other hand, porosity of the titanium coating increased due to the not sufficient deformability of sprayed particles.

Recently, through collaboration among NIMS, Kagoshima University and Plasma Giken Co. Ltd., the combustion pressure of WS has been increased from $\sim 1$ to $4 \mathrm{MPa}$ with some internal design modifications (fuel injector, expansion nozzle) (Ref 28), aiming to accelerate particles toward substrate with velocity over $1000 \mathrm{~m} / \mathrm{s}$.

In this study, the particle temperature and velocity were systematically varied by the combustion pressure, spray distance and barrel length in order to find how these parameters affect the microstructure (porosity and oxidation content) and mechanical properties (microhardness) of the deposited Ti-6Al-4V coatings. The research ultimately aims to determine the optimal parameters to produce dense and uniform Ti-6Al-4V coatings applicable to form and repair metal components.

\section{Experimental Procedures}

\subsection{Materials}

In this study, commercially available Ti-6Al-4V ELI* powder (Raymor Industries, Ltd., Québec, Canada) manufactured by gas atomization with near-spherical morphology was used. The powder size ranged from 1 to $75 \mu \mathrm{m}$ with the mean of about $35 \mu \mathrm{m}$ (Fig. 1a). The particle size was measured by the laser scattering method (Microtrac HRA, Nikkiso Co., Ltd., Japan) and confirmed by SEM microscopy (Fig. 1b).

*Ti6-Al-4V ELI (grade 23) is very similar to Ti-6Al-4V (grade 5), except that Ti-6Al-4V ELI contains reduced levels of nitrogen, carbon, iron, and especially oxygen. ELI is a short for "Extra Low Interstitial" and this feature provides improved ductility and good fracture toughness for the Ti-6Al-4V ELI material. 
(a)

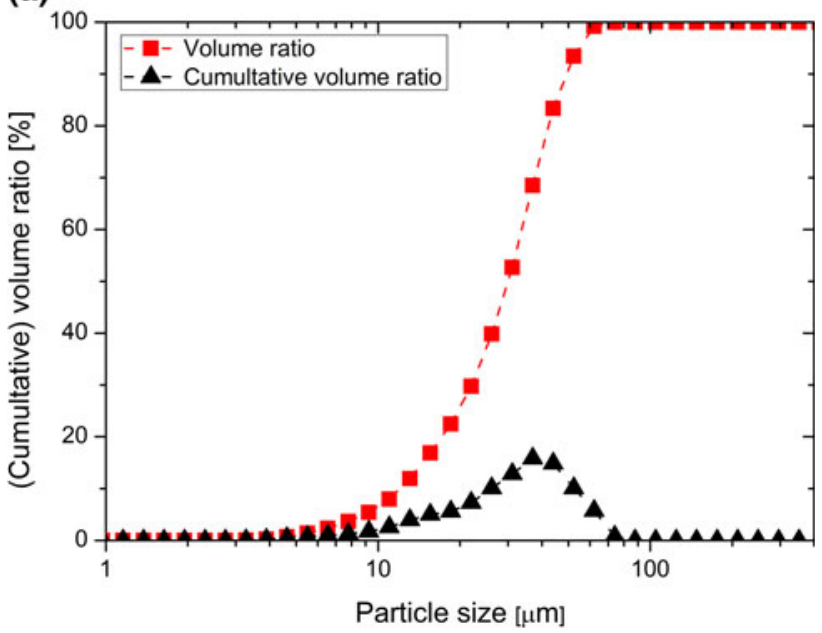

(b)

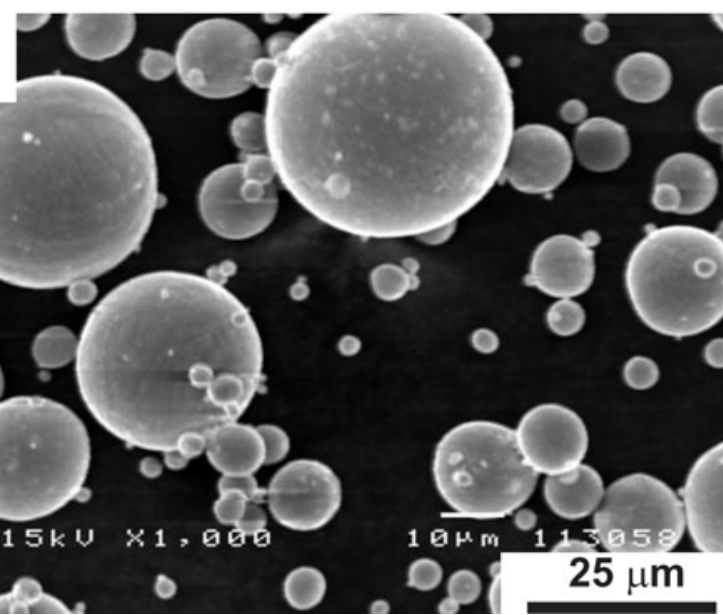

Fig. 1 Particle size distribution (a) and SEM/SE image (b) of feedstock Ti-6Al-4V ELI powder

Table 1 shows the specification (chemical composition) of the Ti-6Al-4V ELI powder provided by the powder maker. Because oxygen content has a significant impact on the microstructure and mechanical properties of the Ti-6Al-4V ELI coatings it was also analyzed by an inert gas fusion method (Ref 20), which confirmed an oxygen content of 0.155 mass \% existed in the feedstock powder.

Substrates were $100 \times 50 \times 5 \mathrm{~mm}$ plates made of low carbon steel JIS: SS400, which were grit-blasted with alumina powder and cleaned using acetone before spraying. Additionally, mirror-polished plates of stainless steel JIS: SUS 304 with dimensions of $50 \times 10 \times 5 \mathrm{~mm}$ were used for the single splats deposition.

\subsection{Warm Spray Conditions}

In order to examine how spray parameters affect the microstructure of Ti-6Al-4V coatings, a series of samples was prepared by the high-pressure WS with various nitrogen flow rates, barrel lengths, and spray distances as shown in Table 2 (No. 1-10). The mixture ratio of kerosene to oxygen was fixed at the stoichiometric ratio for
Table 1 Chemical composition of feedstock Ti-6Al-4V ELI powder

\begin{tabular}{lccccccccc}
\hline Element & $\begin{array}{c}\mathbf{N} \\
\max \end{array}$ & $\begin{array}{c}\mathbf{C} \\
\max \end{array}$ & $\begin{array}{c}\mathbf{H}_{2} \\
\max \end{array}$ & $\begin{array}{c}\text { Fe } \\
\max \end{array}$ & $\begin{array}{c}\mathbf{O}_{2} \\
\max \end{array}$ & $\mathbf{A l}$ & $\mathbf{V}$ & $\begin{array}{c}\text { Residual } \\
\text { (total) }\end{array}$ & $\mathbf{T i}$ \\
\hline$($ mass \%) & 0.01 & 0.02 & 0.004 & 0.14 & 0.155 & 6 & 4 & 0.1 & Balance \\
\hline
\end{tabular}

complete combustion. With increase in nitrogen flow rate, it was necessary to control the flow of the fuel and oxygen to maintain the combustion pressure at a constant level. Another series of samples was formed with the use of lowpressure WS for comparison. While nitrogen flow rate was varied between 0.5 and $1.5 \mathrm{~m}^{3} / \mathrm{min}$, the spray distance between the barrel exit and target position $(200 \mathrm{~mm})$ as well as barrel length $(200 \mathrm{~mm}$ ) were kept constant (No. 11-13) in order to investigate how combustion pressure affects microstructure by comparing with the corresponding samples by the high-pressure WS. (No. 1-4).

All deposited coatings were approximately from 0.29 to $0.56 \mathrm{~mm}$ in thickness. In addition, one layer of Ti-6Al-4V particles were deposited on the mirror-polished surface of substrate with both the low- and high-pressure WS by a single pass of spray gun in order to further evaluate the effects of particles temperature on the deformation of deposited particles. The conditions for single splats formation are listed in Table 3.

\subsection{Coating Characterization}

For measurement of in-flight particles velocity, the laser particles image velocimetry (PIV: Seika Sangyo, Tokyo, Japan) was used. The pulsed laser sheet illuminates the sprayed particles and the positions of the particles during two consecutive laser pulses are recorded by a double-frame CCD video camera. The whole flow field is divided into elementary cells, where the average displacement of particles is calculated on the basis of cross correlational analysis. By dividing the displacement by the time interval between the laser pulses, the average velocity for the particles included in the cell is obtained.

Cross-sections of the Ti-6Al-4V coatings were obtained by embedding a specimen in a cold-mounting resin followed by several steps of grinding with the use emery papers and subsequent polishing with diamond and alumina suspension to $1 \mu \mathrm{m}$ finish. Microstructure of the coatings as well as deposited single splats were investigated by using the back scattered electron (BSE) mode of scanning electron microscopy (S-4700 FE-SEM, Hitachi Ltd., Tokyo, Japan).

Porosity was evaluated by image analysis performed on cross-sectional backscattered electron micrographs (ImageJ: National Institutes of Health, Maryland, United States). For each spraying condition, at least 10 images taken in the middle part of the formed coating were used to determine the porosity value, which was calculated as a mean value of results determined for all individual images.

Oxygen content of as-deposited coatings was analyzed by the inert gas fusion method (EMGA-620W, Horiba Ltd., Kyoto, Japan). The details about this method may be 
Table 2 Warm spray conditions for Ti-6Al-4V coatings

\begin{tabular}{|c|c|c|c|c|c|c|c|c|}
\hline No. & $\begin{array}{c}\text { Condition } \\
\text { ID }\end{array}$ & $\begin{array}{c}\text { Combustion } \\
\text { pressure, MPa }\end{array}$ & $\begin{array}{l}\text { Kerosene, } \\
\mathrm{dm}^{3} / \mathrm{min}\end{array}$ & $\begin{array}{l}\text { Oxygen, } \\
\mathrm{m}^{3} / \mathrm{min}\end{array}$ & $\begin{array}{c}\text { Nitrogen, } \\
\mathrm{m}^{3} / \mathrm{min}\end{array}$ & $\begin{array}{c}\text { Spray distance, } \\
\mathbf{m m}\end{array}$ & $\begin{array}{c}\text { Barrel length, } \\
\text { mm }\end{array}$ & $\begin{array}{l}\text { Powder feed } \\
\text { rate, g/min }\end{array}$ \\
\hline 1 & HP-WS-0.5 & $3.9-4.2$ & 0.480 & 0.980 & 0.5 & 200 & 200 & 45 \\
\hline 2 & HP-WS-1.0 & & 0.380 & 0.780 & 1 & & & \\
\hline 3 & HP-WS-1.25 & & 0.335 & 0.685 & 1.25 & & & \\
\hline 4 & HP-WS-1.5 & & 0.290 & 0.590 & 1.5 & & & \\
\hline 5 & HP-WS-1.0_b & & 0.380 & 0.780 & 1 & 200 & 100 & \\
\hline 6 & HP-WS-1.0_c & & & & & 200 & 250 & \\
\hline 7 & HP-WS-1.0_d & & & & & 120 & 200 & \\
\hline 8 & HP-WS-1.5_b & & 0.290 & 0.590 & 1.5 & 200 & 100 & \\
\hline 9 & HP-WS-1.5_c & & & & & 200 & 250 & \\
\hline 10 & HP-WS-1.5_d & & & & & 120 & 200 & \\
\hline 11 & LP-WS- $0.5^{-}$ & $0.9-1$ & 0.391 & 0.805 & 0.5 & 200 & 200 & \\
\hline 12 & LP-WS-1.0 & & 0.347 & 0.714 & 1 & & & \\
\hline 13 & LP-WS-1.5 & & 0.303 & 0.623 & 1.5 & & & \\
\hline
\end{tabular}

Table 3 Warm spray conditions for Ti-6Al-4V single splats

\begin{tabular}{|c|c|c|c|c|c|c|c|c|}
\hline No. & $\begin{array}{c}\text { Condition } \\
\text { ID }\end{array}$ & $\begin{array}{c}\text { Combustion } \\
\text { pressure, MPa }\end{array}$ & $\begin{array}{c}\text { Kerosene, } \\
\mathrm{dm}^{3} / \mathrm{min}\end{array}$ & $\begin{array}{l}\text { Oxygen, } \\
\mathrm{m}^{3} / \mathrm{min}\end{array}$ & $\begin{array}{c}\text { Nitrogen, } \\
\mathrm{m}^{3} / \mathrm{min}\end{array}$ & $\begin{array}{c}\text { Spray distance, } \\
\mathbf{m m}\end{array}$ & $\begin{array}{c}\text { Barrel length, } \\
\text { mm }\end{array}$ & $\begin{array}{l}\text { Powder feed } \\
\text { rate, g/min }\end{array}$ \\
\hline 1 & HP-WS-0.75 & $3.9-4.2$ & 0.480 & 0.980 & 0.5 & 200 & 200 & 45 \\
\hline 2 & HP-WS-1.0 & & 0.380 & 0.780 & 1 & & & \\
\hline 3 & HP-WS-1.25 & & 0.335 & 0.685 & 1.25 & & & \\
\hline 4 & HP-WS-1.5 & & 0.290 & 0.590 & 1.5 & & & \\
\hline 5 & LP-WS-0.5 & $0.9-1$ & 0.391 & 0.805 & 0.5 & & & \\
\hline 6 & LP-WS-1.0 & & 0.347 & 0.714 & 1 & & & \\
\hline 7 & LP-WS-1.5 & & 0.303 & 0.623 & 1.5 & & & \\
\hline
\end{tabular}

found in ASTM standard E1409-08 "Standard Test Method for Determination of Oxygen and Nitrogen in Titanium and Titanium Alloys by the Inert Gas Fusion Method."

Deposition efficiency was measured by spraying onto a 100 by $50 \mathrm{~mm}$ low carbon steel JIS: SS400 plate substrate. By scanning the spraying torch with velocity $(v)$ transversely over the substrate with width $(B)$ for $\mathrm{n}$ times during a period $(t)$ and measuring the weight gain $(\Delta W)$ of the substrate and the weight $(w)$ of the powder consumed during the run, the deposition efficiency was given by:

$\eta=\frac{\Delta W}{w} \times \frac{v t}{n B}$

The factor $v t / n B$ is included to take into account the loss of powder by overspraying.

Microhardness measurements were performed on the mirror-polished cross-sections of the coatings by a semiautomatic microhardness tester (MVK-E, Akashi Co., Ltd., Kanagawa, Japan) equipped with a Vickers indenter. For each spraying condition at least 10 indentations were carried out with $0.5 \mathrm{kgf}$ loading for $15 \mathrm{~s}$.

Surface roughness parameter $\left(R_{\mathrm{a}}\right)$ was evaluated by a surface profilometer (SurfTest SJ-201, Mitutoyo Co., Ltd., Tokyo, Japan). For each spraying condition at least 7 measurements were carried out with a sample length of $7 \mathrm{~mm}$.

For calculation of the flattening ratio of single splats, an optical digital microscope (VHX-2000, Keyence Co., Ltd, Osaka, Japan) was used, which allows to display 3D images by compiling images taken at different focus positions. One can perform post processing measurements of visualized elements such as splat height, diameter, and volume. Flattening ratio $(h / d)$ of deposited particles was calculated by dividing the splat height by its diameter. Initial diameter of particles was calculated under the assumption of a constant volume for particles before and after impact. In order to obtain representative values for each spraying condition, 20 particles were measured.

\subsection{Numerical Calculations of Warm Spray}

The numerical calculations of the gas flow of the HP-WS gun consists of three parts; the stagnant conditions of the $\mathrm{CC}$ and $\mathrm{MC}$, internal gas flow from the throat of convergingdiverging (C-D) nozzle to the barrel exit, and the external jet flow. The main assumptions used to simplify the calculation of $\mathrm{CC}$ and $\mathrm{MC}$ are listed below;

(1) The gas in the $\mathrm{CC}$ consists of 8 gas species; $\mathrm{CO}, \mathrm{CO}_{2}$, $\mathrm{H}_{2} \mathrm{O}, \mathrm{H}_{2}, \mathrm{H}, \mathrm{OH}, \mathrm{O}_{2}$, and $\mathrm{O}$ (Ref 29).

(2) Each gas species follows the equation of state of the ideal gas.

(3) The combustion gas mixes with the $\mathrm{N}_{2}$ gas uniformly at the moment of entering the MC.

(4) The gases in CC and MC are stagnant, and are in chemical equilibrium condition.

The stagnant condition in the $\mathrm{CC}$ and $\mathrm{MC}$ are calculated by the software (Ref 30 ) developed by NASA. The equivalence ratio in the $\mathrm{CC}$ was set at 1 . The flow rate of fuel (kerosene), as well as oxygen, is set at specific value so 
that the pressure in the $\mathrm{CC}$ is kept at $4 \mathrm{MPa}$ for each $\mathrm{N}_{2}$ flow rate of $0.5,1.0,1.5,2.0 \mathrm{~m}^{3} / \mathrm{min}$. The cooling rate of the $\mathrm{CC}$ and $\mathrm{MC}$ were set at 0.20 and 0.14 (Ref 31), respectively, based on the experimental data of watercooled LP-WS gun.

After obtaining gas pressure, temperature and other thermodynamic properties in the $\mathrm{MC}$, the gas flow from the throat of the C-D nozzle to the barrel exit was calculated. Main assumptions used are listed below;

(1) The gas flow is steady and chemically frozen.

(2) The gas flow is quasi-one-dimensional, including the effects fluid dynamic friction and heat transfer along the inner wall surface.

(3) The velocity and temperature of the gas flow are not affected by the particle flow.

The diameters of the throat and barrel were set at 0.0042 and $0.011 \mathrm{~m}$, respectively. The cooling rate of the barrel was calculated by an experimentally obtained equation for LP-WS proposed in (Ref 31).

The gas velocity and temperature of the supersonic jet flow along the center line were calculated by an empirical equation of the potential-core length (Ref 32) and semiempirical equations of velocity and total enthalpy (Ref 33, 34) downstream of the potential-core. When the jet flow is over- or under-expanded at the barrel exit, the jet is modeled such that the gas flow at the barrel exit is compressed or expands isentropically to the atmospheric pressure, resulting in a discontinuous change in velocity, temperature, density, and pressure at the barrel exit.

After obtaining the gas velocity, temperature, and density, the particle velocity and temperature were calculated. The following main assumptions were used to calculate the particle behaviour traveling in the gas flow.

(1) Single particle travels along the nozzle/jet axis.

(2) The particle is spherical in shape.

(3) The acceleration of particle in the gas flow is caused only by gas dynamic drag force.

(4) The particle is heated by the gas through heat transfer and heat radiation.

(5) Temperature in the particle is uniform.

The particle selected in the present calculations is $30 \mu \mathrm{m} \mathrm{Ti}$, with its bulk density and specific heat of $4,510 \mathrm{~kg} / \mathrm{m}^{3}$ and $528 \mathrm{~J} /(\mathrm{kg} \mathrm{K})$, respectively. The particle was injected in the gas flow at $10 \mathrm{~m} / \mathrm{s}$ and $300 \mathrm{~K}$ at $10 \mathrm{~mm}$ downstream of the entrance of the barrel. The velocity of the particle was calculated by solving the Newton's equation of motion, which is written as;

$m_{\mathrm{p}} u_{\mathrm{p}} \frac{\mathrm{d} u_{\mathrm{p}}}{\mathrm{d} x}=\frac{1}{2} c_{\mathrm{d}} \rho_{\mathrm{g}}\left(u_{\mathrm{g}}-u_{\mathrm{p}}\right) \cdot\left|u_{\mathrm{g}}-u_{\mathrm{p}}\right| A_{\mathrm{p}}$,

where $x$ is the axial distance along the center line from the nozzle throat, $m_{\mathrm{p}}$ is the mass of the particle, $u_{\mathrm{p}}$ is the particle velocity, $u_{\mathrm{g}}$ is the gas velocity, $\rho_{\mathrm{g}}$ is the gas density, $A_{\mathrm{p}}$ is the projected area of the particle, $c_{\mathrm{d}}$ is the drag coefficient of the particle, respectively. The drag coefficient of the particle (sphere) was calculated by a database constructed from the experimental data (Ref 35), along with high temperature correction (Ref 36). The temperature of the particle was obtained by numerically integrating the energy balance equation, which is written as;

$m_{\mathrm{p}} C u_{\mathrm{p}} \frac{\mathrm{d} T_{\mathrm{p}}}{\mathrm{d} x}=\alpha\left(T_{\mathrm{g}}-T_{\mathrm{p}}\right) \cdot A_{\mathrm{s}}$,

where $T_{\mathrm{p}}$ is the particle temperature, $C$ is the specific heat of the particle, $T_{\mathrm{g}}$ is the gas temperature, $A_{\mathrm{s}}$ is the surface area of the particle, $\alpha$ is the heat transfer coefficient which can be given as;

$\alpha=\frac{\lambda_{\mathrm{f}} N_{\mathrm{u}}}{d_{\mathrm{p}}}$

Here, $N_{\mathrm{u}}$ is the Nusselt number, $d_{\mathrm{p}}$ is the particle diameter, and $\lambda_{\mathrm{f}}$ is the thermal conductivity of the gas. Further detail of the model equations can be found in (Ref 37).

\section{Results and Discussion}

\subsection{Particles Velocity and Temperature}

Numerical simulations and experiments carried out previously by Kuroda et al. (Ref 17) for $30 \mu \mathrm{m}$ titanium particles sprayed with the use of low-pressure WS system showed that nitrogen flow rate affects mainly particles temperature which be changed in a range from about 750 to $1500 \mathrm{~K}$. An interesting observation was that particles velocity profiles were almost unaffected by the nitrogen flow rate and it was about $750 \mathrm{~m} / \mathrm{s}$ at a spray distance of $200 \mathrm{~mm}$. The point was that increase in the gas density by addition of nitrogen compensates the decrease of gas velocity. Similar calculations have been carried out for the novel high-pressure WS system. Katanoda et al. (Ref 28) performed optimization procedure of the nozzle geometry by using one-dimensional calculations, aiming to increase the velocity of $30 \mu \mathrm{m}$ titanium particles. The results of the calculations in the form of velocity and temperature profiles are shown in Fig. 2(a) and (b), respectively.

Here, distance $x=0$ corresponds to barrel exit of the nozzle and powder feed ports are situated about $200 \mathrm{~mm}$ upstream. When the gas expand through the nozzle (Fig. 2a), its velocity increases rapidly and then decreases gradually along the barrel length due to the friction with inner wall of the barrel. Outside the barrel the gas velocity remains constant in the potential-core region and finally decreases rapidly due to mixing with the ambient air. It should be noted that gas velocity is higher with lower nitrogen flow rate along the gun and in the potential-core region of the jet. This effect is mainly due to the higher gas temperature and was explained in detail in the previous paper on the WS (Ref 19). An interesting point is that velocity profiles of $30 \mu \mathrm{m}$ titanium particles are only slightly affected by nitrogen flow rate. This is attributed to the increase in gas density by addition of nitrogen, which partially compensated the decreased gas velocity. 
Figure 2(b) shows significant effect of mixing nitrogen on the temperature of combustion gas and $30 \mu \mathrm{m}$ titanium particles. At the beginning the gas temperature decreases rapidly due to expansion through the nozzle and then gradually decreases for 0.5 and $1.0 \mathrm{~m}^{3} / \mathrm{min}$ and increases
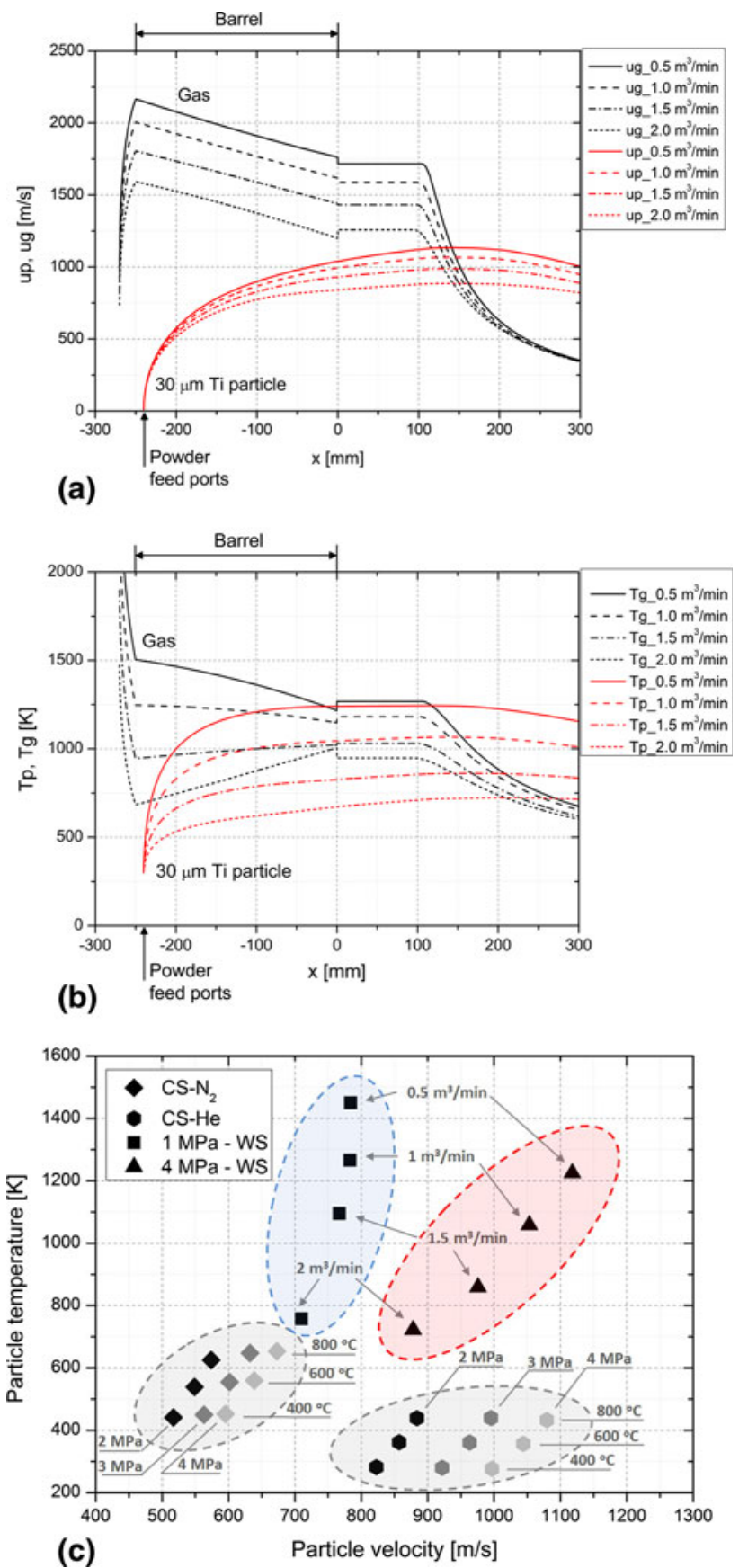

Fig. 2 Numerical simulation profiles for warm spraying $30 \mu \mathrm{m}$ titanium particles based on various process gas flow rates, starting from the combustion chamber to a spray distance of about $200 \mathrm{~mm}$. (a) Gas and particle velocity profiles; (b) gas and particle temperature profiles; (c) process map showing the ranges of particle temperatures and velocities achievable by low- and highpressure warm spray and CS (with the use of nitrogen or helium as a powder carrier gas) for 1.5 and $2 \mathrm{~m}^{3} / \mathrm{min}$ nitrogen flow rates depending on the extent of the heat loss to the water-cooled through the barrel against the temperature recovery due to the deceleration of the gas flow by friction with inner wall of the barrel. After exiting the barrel, the gas temperature remains constant in the potential-core region and then decreases rapidly due to the mixing with the ambient air.

In summary, the numerical calculations show that there is possibility to control particles temperature from about 750 to $1300 \mathrm{~K}$ at $x=200 \mathrm{~mm}$, where substrates are normally placed for WS, while at the same time to accelerate the $30 \mu \mathrm{m}$ titanium particles to more than $1000 \mathrm{~m} / \mathrm{s}$, which is significantly higher than for low-pressure WS $(750 \mathrm{~m} / \mathrm{s})$.

In Fig. 2(c), typical ranges of particles velocity and temperature at substrate position of $200 \mathrm{~mm}$ downstream the barrel, calculated by the numerical simulation for lowand high-pressure WS, as well as for CS with the use on nitrogen and helium as the propellant gas, are presented. For CS substrate position was $10 \mathrm{~mm}$ away from the nozzle exit. The gas temperature for CS was varied in the range of 673 to $1073 \mathrm{~K}$ for each particular gas pressure $(2,3$, and $4 \mathrm{MPa})$. An interesting point of high-pressure WS in contrast to low-pressure WS is that, there is clear decrease in particles velocity while decreasing gas temperature. It seems that increase in gas density by addition of nitrogen is not sufficient to compensate for the decrease of gas velocity. Notwithstanding, the most important advantage of the novel WS is to achieve particles velocity comparable with the values for CS-He. Thus, relatively high particles velocity in combination with high temperature should give an opportunity to form coatings of less sprayable materials like Ti-6Al-4V. These plots indicate the specific combustion conditions at which Ti-6Al-4V WS coatings were prepared in the experiments (Table 2).

Figure 3 shows profiles of particles velocity obtained by the PIV method as a function of spray distance for $\mathrm{Ti}$ (TILOP, CP-Ti) and Ti-6Al-4V powders sprayed with the use high-pressure WS system at $1.0 \mathrm{~m}^{3} / \mathrm{min}$ nitrogen flow rate. The range of velocity for TILOP and Ti-6Al-4V

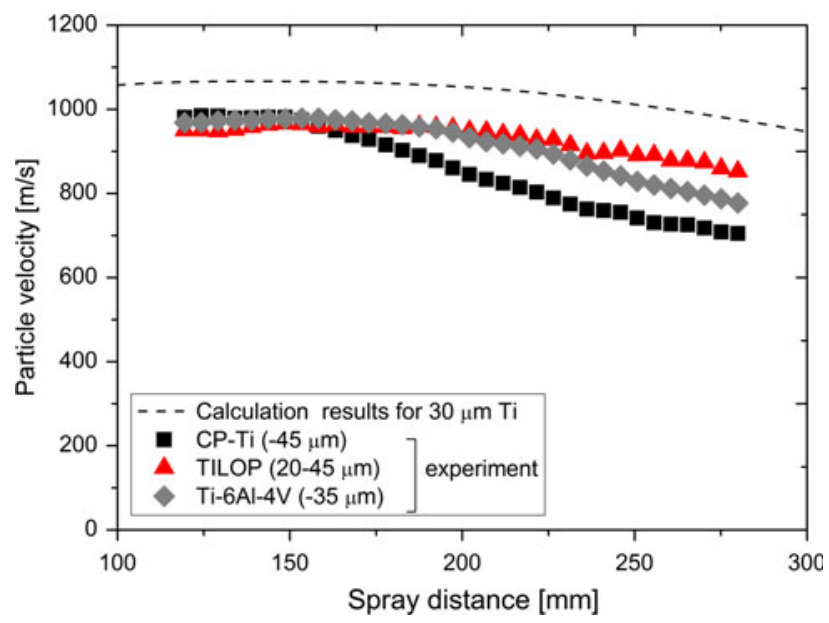

Fig. 3 Particles velocity profiles for Ti-6Al-4V, TILOP, and $\mathrm{CP}-\mathrm{Ti}$ powders obtained with the use of high-pressure warm spray system at $1.0 \mathrm{~m}^{3} / \mathrm{min}$ nitrogen flow rate 
powders was at a similar level (for typical spray distance of $200 \mathrm{~mm}$ ) and amounted to about $960 \mathrm{~m} / \mathrm{s}$. However, they were not as fast as predicted by calculations $(\sim 1050 \mathrm{~m} / \mathrm{s})$ but exhibited fairly significant increase in contrast to the low-pressure WS $(750 \mathrm{~m} / \mathrm{s})$. A possible reason why the experimental values were lower than calculation is that the simulation was for titanium particles of $30 \mu \mathrm{m}$ in diameter. Actually, however, particles deposited by WS had a size distribution of powder containing coarser particles. It is well known for kinetic spray process that both particle temperature and velocity depend strongly on the particles size. Small particles immediately after injection reach the values of temperature and velocity close to these of the process gas but are then rapidly cooled down and decelerated beyond the exit of the nozzle. On the contrary, changes of particles temperature and velocity for bigger particles are slower due to their higher heat capacity and inertia ( $\operatorname{Ref} 38,39)$. By the same principle it can be explained why for CP-Ti $(-45 \mu \mathrm{m})$ and Ti-6Al-4V $(-35 \mu \mathrm{m})$ powders slightly lower velocity was observed at longer spray distances over $150 \mathrm{~mm}$ as compared to the sieved TILOP (20 to $45 \mu \mathrm{m}$ ). Since fine particles below $20 \mu \mathrm{m}$ are included in CP-Ti and Ti-6Al-4V powders, they should be decelerated more readily at larger distances from the barrel exit.

\subsection{Effects of Barrel Length and Spray Distance}

To find out the optimal conditions for warm spraying Ti-6Al-4V coatings, two spray parameters were examined firstly such as the barrel length and spray distance. Figure 4 shows the cross-sectional backscattered SEM images of Ti-6Al-4V coatings fabricated by high-pressure WS as a function of the barrel length at two nitrogen flow
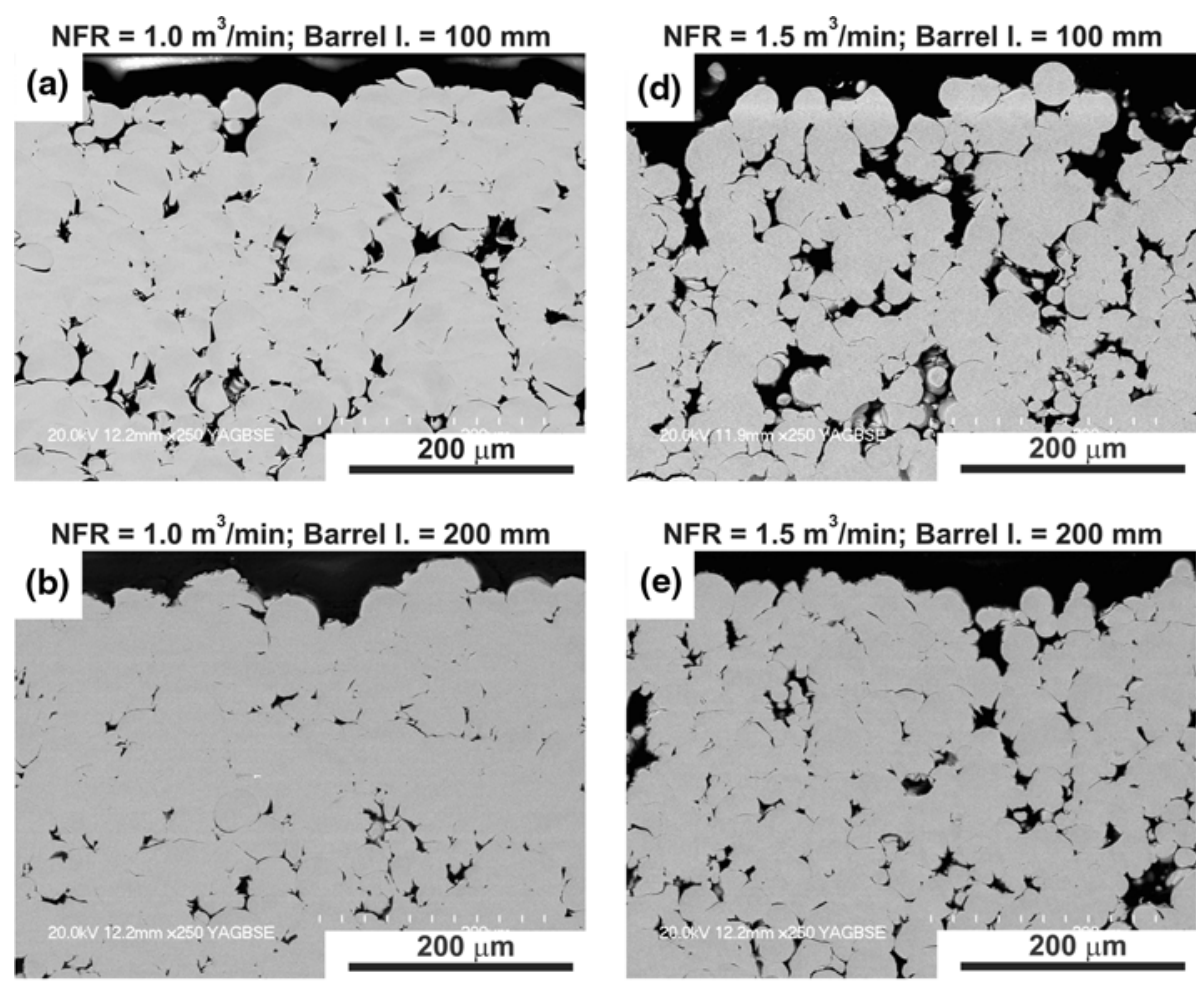

$\mathrm{NFR}=1.0 \mathrm{~m}^{3} / \mathrm{min} ;$ Barrel $\mathrm{l} .=250 \mathrm{~mm}$
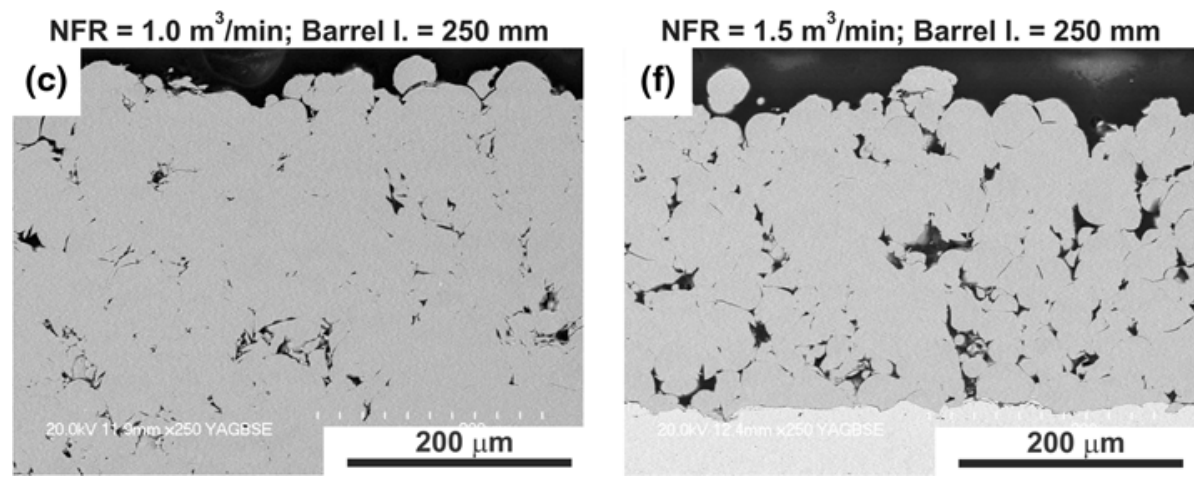

Fig. 4 Cross-sectional backscattered SEM images of Ti-6Al-4V coatings fabricated by high- pressure warm spray system at two nitrogen flow rates of $1.0 \mathrm{~m}^{3} / \mathrm{min}(\mathrm{a}-\mathrm{c})$ and $1.5 \mathrm{~m}^{3} / \mathrm{min}(\mathrm{d}-\mathrm{f})$ as a function of barrel length 
rates of $1 \mathrm{~m}^{3} / \mathrm{min}$ (Fig. $4 \mathrm{a}-\mathrm{c}$ ) and $1.5 \mathrm{~m}^{3} / \mathrm{min}$ (Fig. $4 \mathrm{~d}-\mathrm{f}$ ), respectively.

When sprayed with low nitrogen flow rate, especially with low-pressure WS, the cross-section of Ti-6Al-4V coating observed with the use of BSE mode contains at least 3 ranges of gray scale contrast which represent various features of microstructure (Fig. 9a). The light gray color of the image represents the inner part of deposited particles, while the black one represents porosity. This is because there is little back scattered electrons escaped from the place of materials discontinuity such as porosity. Intermediate range of colors usually represents oxides, which often appear at the boundary of deposited particles. The ratio of porous area to the area of the coating was determined as porosity of the coating.

Figure 4 clearly indicates that for both series the coatings formed with the shortest barrel $(100 \mathrm{~mm})$ exhibited more porous microstructures than these sprayed with the other two longer barrels (200 and $250 \mathrm{~mm}$ ). Porosity calculated by image analysis was about $4.7 \%$ for the coating formed at $1.0 \mathrm{~m}^{3} / \mathrm{min}$ and $7.5 \%$ for the coating sprayed at $1.5 \mathrm{~m}^{3} / \mathrm{min}$ nitrogen flow rate with barrel length of $100 \mathrm{~mm}$. Increasing the barrel length to $200 \mathrm{~mm}$ resulted in the porosity of about 1.1 and $4.6 \%$, respectively. However, further increase of the barrel length resulted in a slight increase of porosity as shown in Fig. 5(a) and (b). On the other hand, there was no clearly change in the oxygen content while increasing the barrel length. These data suggest an optimal barrel length of $200 \mathrm{~mm}$ to obtain the best quality Ti-6A-14V coating. The results of numerical calculations performed for HVOF (Ref 40, 41), CS (Ref 37) and WS (Ref 19,28) show that increase in barrel length results in higher particles velocity due to the particles velocity approach the gas velocity. On the other hand, excessive lengthening of the barrel can lead to several negative effects. The most important ones are the heat losses by nozzle cooling and pipe friction loss. Sakaki and Shimizu (Ref 41) reported for HVOF that since these losses increase with the barrel length, velocity, and temperature of the gas and particles decrease with an increase in the barrel length. Although, there was no clear decrease of particles velocity and temperature for high pressure WS even at $250 \mathrm{~mm}$ barrel length (Fig. $2 \mathrm{~b}$ and c), the decrease of gas velocity and temperature along barrel length due to heat friction with inner wall can explain further increase of the porosity value while increasing barrel length above the optimal value of $200 \mathrm{~mm}$.

Above considerations were confirmed by measurements of particles velocity performed for $30 \mu \mathrm{m}$ titanium particles. Figure 6 shows velocity profiles obtained with the use of high-pressure WS system at $1.0 \mathrm{~m}^{3} / \mathrm{min}$ nitrogen flow rate, which was equipped with a barrel of different lengths. These results indicate that there is merit in using a longer barrel up to $200 \mathrm{~mm}$ to increase the velocity, but it becomes less effective at $250 \mathrm{~mm}$ possibly because of the heat and frictional loss by the gas with the barrel wall.

Spray distance is another parameter which can affect the microstructure of Ti-6Al-4V coatings. Figure 7 shows cross-sectional backscattered SEM micrographs of coatings sprayed by high-pressure WS system at the spray

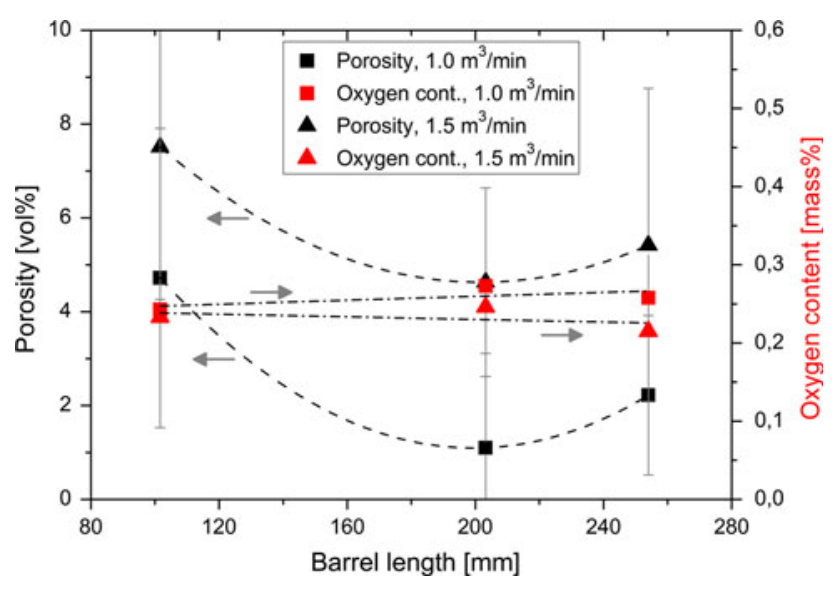

Fig. 5 Porosity and oxygen content of Ti-6Al-4V coatings fabricated by high- pressure warm spray system at two nitrogen flow rates of $1.0 \mathrm{~m}^{3} / \mathrm{min}$ and $1.5 \mathrm{~m}^{3} / \mathrm{min}$ as a function of barrel length

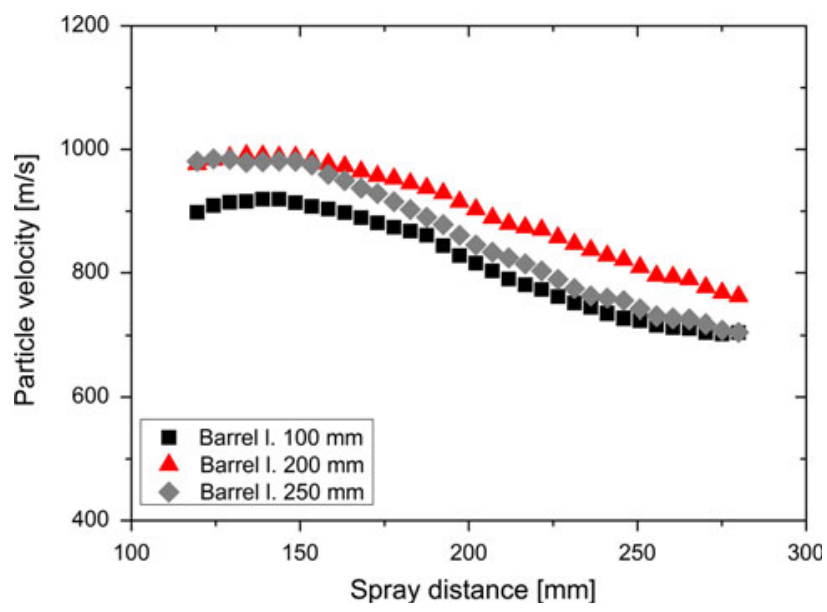

Fig. 6 Titanium particles velocity profiles obtained with the use high-pressure warm spray system at $1.0 \mathrm{~m}^{3} / \mathrm{min}$ nitrogen flow rate as a function of barrel length

distance of 120 and $200 \mathrm{~mm}$ with two different nitrogen flow rates of $0.5 \mathrm{~m}^{3} / \mathrm{min}$ (Fig. 7a and b) and $1.0 \mathrm{~m}^{3} / \mathrm{min}$ (Fig. 7c and d).

Figure 7(a) shows oxide layers represented by darkgray color around splats deposited at the spray distance of $120 \mathrm{~mm}$ with $0.5 \mathrm{~m}^{3} / \mathrm{min}$ of nitrogen flow rate. However, particles sprayed with longer spray distance are not significantly oxidized (Fig. 7b). These findings have been confirmed by the results of porosity and oxygen content analysis shown in Fig. 8. There is clear decrease of both porosity (from 1.25 to $0.35 \%$ ) and oxygen content (from 1.27 to $0.56 \%$ ) with increase of spray distance from 120 to $200 \mathrm{~mm}$ for the coatings formed with particles at higher temperature, i.e., with nitrogen flow rate of $0.5 \mathrm{dm}^{3} / \mathrm{min}$. It is known that outside the barrel of the WS gun, gas velocity increases gradually at the beginning which represents the under-expansion of the jet flow at the barrel exit It then remains constant in the potential-core region outside the barrel, and decreases again due to mixing with the ambient air (Ref 19). This phenomenon has been also found for 

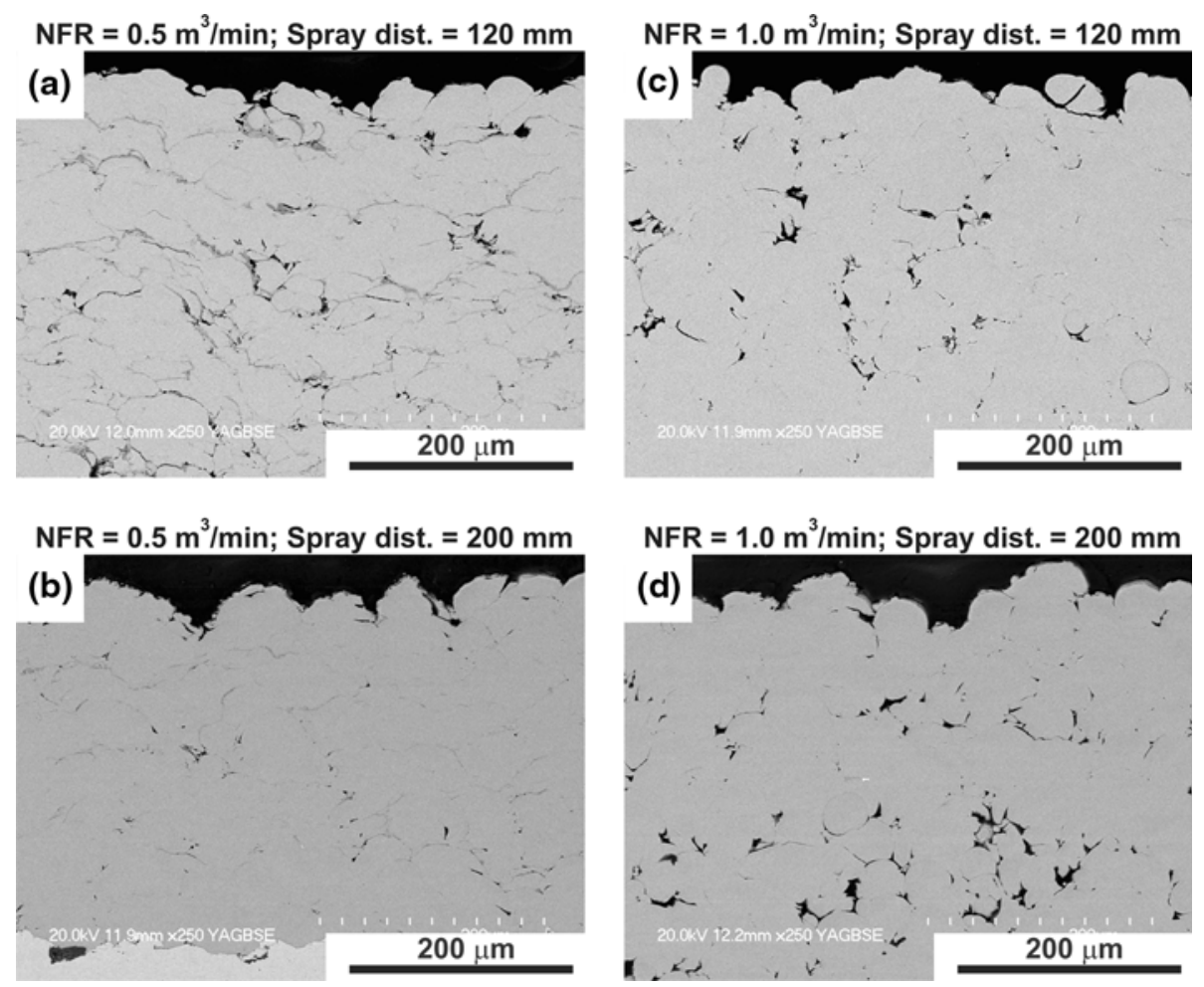

Fig. 7 Cross-sectional backscattered SEM images of Ti-6Al-4V coatings fabricated by high-pressure warm spray system at two nitrogen flow rates of $0.5 \mathrm{~m}^{3} / \mathrm{min}(\mathrm{a}, \mathrm{b})$ and $1.0 \mathrm{~m}^{3} / \mathrm{min}(\mathrm{c}, \mathrm{d})$ as a function of spray distance

other kinetic spray process such as HVOF (Ref 40, 42) or CS (Ref 15, 43). However, according to the numerical calculation (Ref 28) for the high pressure WS, particles velocity and temperature should not change substantially while the spray distance varies in the range from 120 to $200 \mathrm{~mm}$. According to the results of calculations shown in Fig. 2(b), corresponding particles temperatures were 1058 and $1066 \mathrm{~K}$ at spray distance of 120 and $200 \mathrm{~mm}$, respectively. These data suggest that significant oxidation of the sample formed with $120 \mathrm{~mm}$ spray distance is probably due to the effect of combustion flame on the coating surface during the deposition process. Moreover, these findings are consistent with the results of oxygen content measurement performed for titanium coatings sprayed by WS (Ref 20). Kawakita et al. reported that there is an optimal spray distance around $190 \mathrm{~mm}$, which permits the least oxidized coatings. With further increase in spray distance, sprayed titanium powder has more time to react with the air resulting in increase in the oxygen content.

Thus, on the basis of these data and previously performed experiments, optimal values of barrel length $(200 \mathrm{~mm})$ and spray distance $(200 \mathrm{~mm})$ were chosen for investigation of the effects of combustion pressure on the microstructure and mechanical properties of Ti-6Al-4V coatings.

\subsection{Effects of the Combustion Pressure and Nitrogen Flow Rate}

Figure 9 shows cross-sectional backscattered SEM micrographs of Ti-6Al-4V coatings for various nitrogen

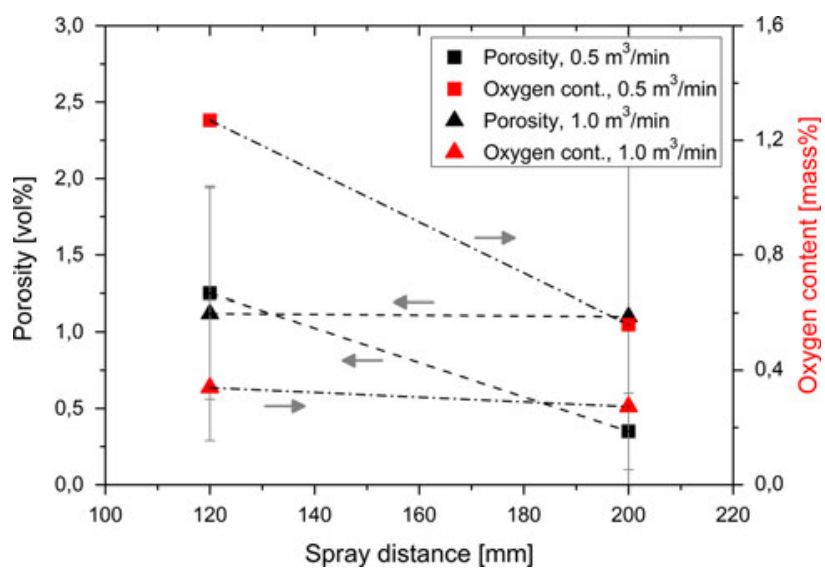

Fig. 8 Porosity and oxygen content of Ti-6Al-4V coatings fabricated by high-pressure warm spray system at two nitrogen flow rates of 0.5 and $1.0 \mathrm{~m}^{3} / \mathrm{min}$ as a function of spray distance

flow rates formed with the use low- and high-pressure WS at the optimal barrel length $(200 \mathrm{~mm})$ and spray distance $(200 \mathrm{~mm})$. The coatings prepared with the lowest nitrogen flow rate exhibited a dense microstructure (Fig. 9a and d), but the particles boundaries can be clearly recognized as the dark gray region along their peripheries, which is especially evident for the coating by the low-pressure WS (Fig. 9a). EDS analysis performed previously by Kim et al. (Ref 44) for titanium deposits identified the existence of oxygen at the particles interfaces. Similarly, the dark gray 

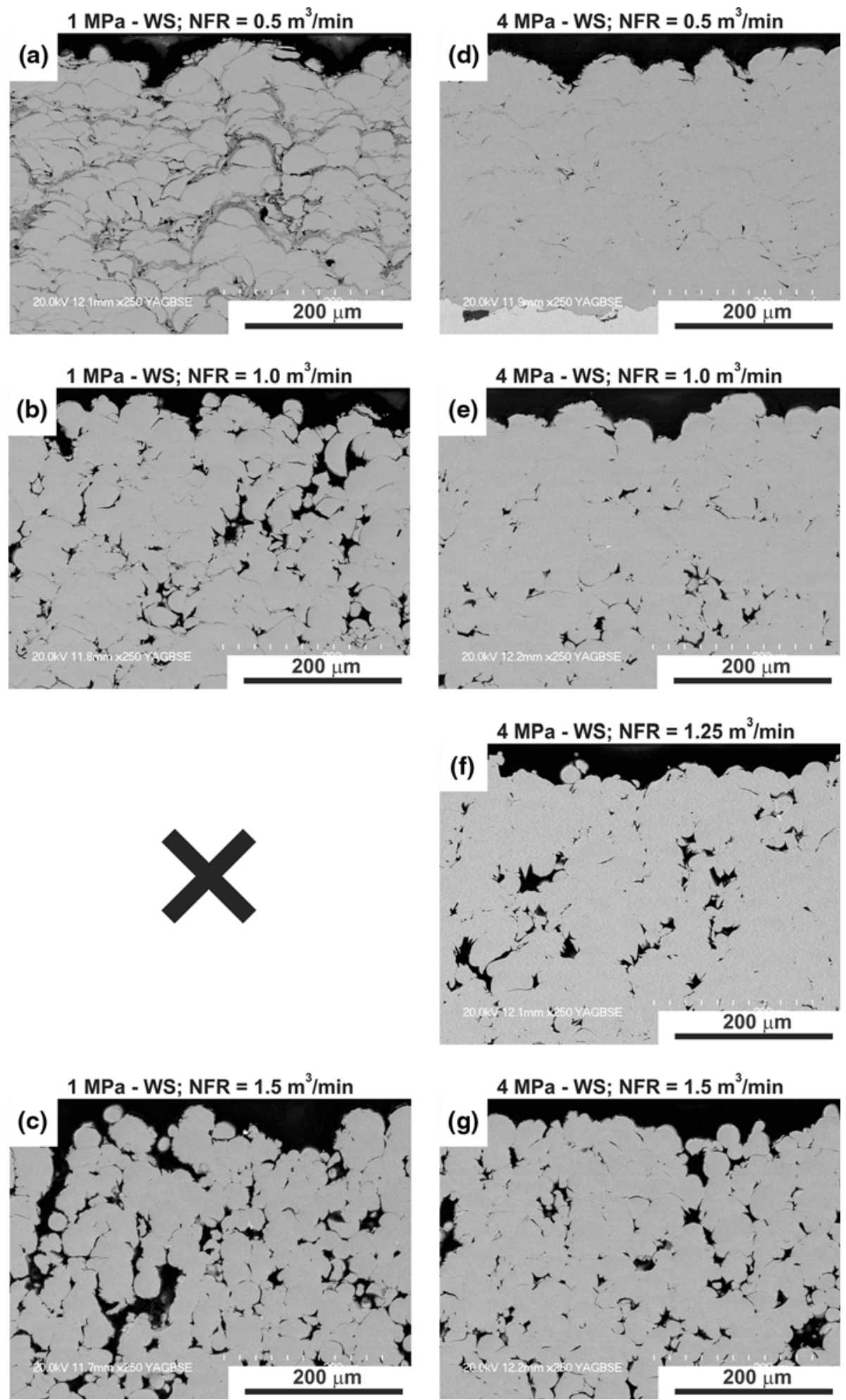

Fig. 9 Cross-sectional backscattered SEM images of Ti-6Al-4V coatings fabricated by low- (a-c) and high-pressure (d-g) warm spray system at various nitrogen flow rates

regions in the Ti-6Al-4V coatings in this study are believed to correspond to oxides or dissolved oxygen in the titanium alloy matrix.
This indicates that with the use $0.5 \mathrm{~m}^{3} / \mathrm{min}$ nitrogen flow rate the temperature was high enough to result in particles oxidation during spraying. Oxidation is much 
more distinct for coatings formed by low-pressure WS due to the higher gas and particles temperature as shown in Fig. 2, which exceeds high-pressure WS by more than $200 \mathrm{~K}$. Several studies suggest that the surface oxide of metallic powder can be easily broken and then removed by severe plastic deformation induced by adiabatic shear instability for both CS (Ref 11, 45) and WS (Ref 21, 46) processes. It seems that for the higher particles velocity resulted in more severe plastic deformation during splats formation, the process of oxides removing is more effective in contrast to the low-pressure WS. Coatings formed with $1.0 \mathrm{~m}^{3} / \mathrm{min}$ nitrogen flow rate, resulted in lower process temperature, were also dense but recognizable dark gray boundaries disappeared in BSE micrographs (Fig. 9b and e). Coatings sprayed with a $1.25 \mathrm{~m}^{3 /} \mathrm{min}$ (Fig. 9f) and $1.5 \mathrm{~m}^{3 /}$ min (Fig. 9c and g) nitrogen flow rates became cleaner, i.e., no gray regions representing oxides can be recognized, but became more porous.

When the microstructure of the coatings formed with low- and high-pressure WS systems are compared, it is obvious that both porosity and oxides content of coatings formed by high-pressure WS are significantly lower than coatings sprayed by low-pressure WS. Subsequently performed porosity analysis and oxygen content measurement confirmed this conclusion drawn from SEM images as shown in Fig. 10. The two curves indicate that there exist trade-off relationships between the density and purity of Ti-6Al-4V coatings prepared by each of the two WS systems. It can be clearly seen, however, that the increase of particle velocity by the use of high-pressure WS results in superior quality coatings both in terms of porosity and oxidation.

An optimal nitrogen flow rate for both low- and highpressure WS system may be $1.0 \mathrm{~m}^{3} / \mathrm{min}$ to realize the best balance between porosity and oxygen content. An important point is that high pressure WS allowed to reduce both coatings porosity (from 3.2 to $1.1 \%$ ) and oxygen content (from 0.75 to $0.27 \%$ ) in comparison to low-pressure WS. It should be noted that oxygen level of the feedstock powder was 0.155 mass $\%$.

Figure 11 shows comparison of porosity and oxygen contents obtained for Ti-6Al-4V coatings formed by various thermal spray processes at various conditions. When there is lack of data on oxygen content in the deposited CS samples, points represented oxygen contents for feedstock powder were plotted in Fig. 11; and in addition were marked with arrows pointing to the right, in the direction of higher oxygen content. Li et al. (Ref 27) cold sprayed Ti-6Al-4V with air as the accelerating gas $(2.8 \mathrm{MPa}$, $800 \mathrm{~K}$ ) and argon as the powder carrier gas. Wong et al. (Ref 47) used three powder processing conditions in his study. The coatings were formed with the use of nitrogen as the propellant gas with temperature and pressure of $1,073 \mathrm{~K}$ and $4 \mathrm{MPa}$, respectively. Blose et al. (Ref 3) at first formed coatings with a helium jet in the range of 2.1 to $2.8 \mathrm{MPa}$ and a temperature of 673 to $773 \mathrm{~K}$. After that he significantly decreased the volume of porosity with preheating the Ti-6Al-4V powder by the use of heater coil operating at temperatures between 573 to 973 K. Salimijazi et al. (Ref 48) formed by LPPS the densest coating

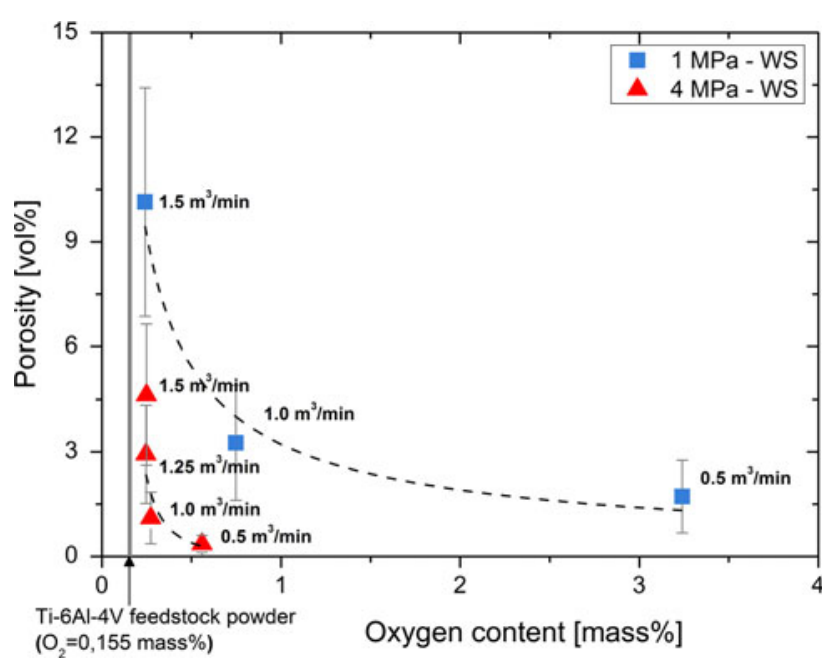

Fig. 10 Porosity and oxygen content for low- and high-pressure warm spray system

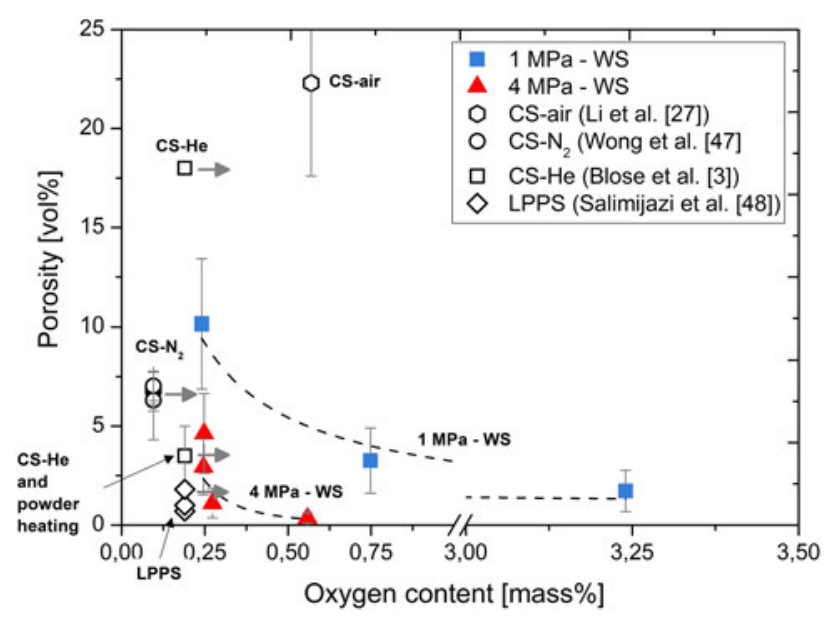

Fig. 11 Correlation between Ti-6Al-4V coatings porosity and oxygen content by warm spray in the present study, cold spray, and low-pressure plasma spray

with the use of a commercial FRVB gun from PlasmaTecknick (Luzern, Switzerland).

The data presented in the graph clearly indicate that high-pressure WS allows to obtain the denser coatings in comparison to CS even with the use of helium as the propellant gas and equipped with powder preheating systems. An important fact is that even for coatings formed with CS some increase of oxygen content after deposition was reported. Kuroda et al. (Ref 21) reported slight increase of oxygen content for the titanium samples formed via CS even with the use of helium as powder carrier gas. What is more, Kim and Kuroda (Ref 46) reported that the surface oxide is not completely removed by the impact another particle onto previously deposited one, and thus thin amorphous oxide remains at the interfaces. Similar conclusions have been also found for CS coating of $\mathrm{Cu}$ (Ref 45) and Al (Ref 49). Therefore, the values of oxygen content in CS feedstock powders plotted in the Fig. 6 

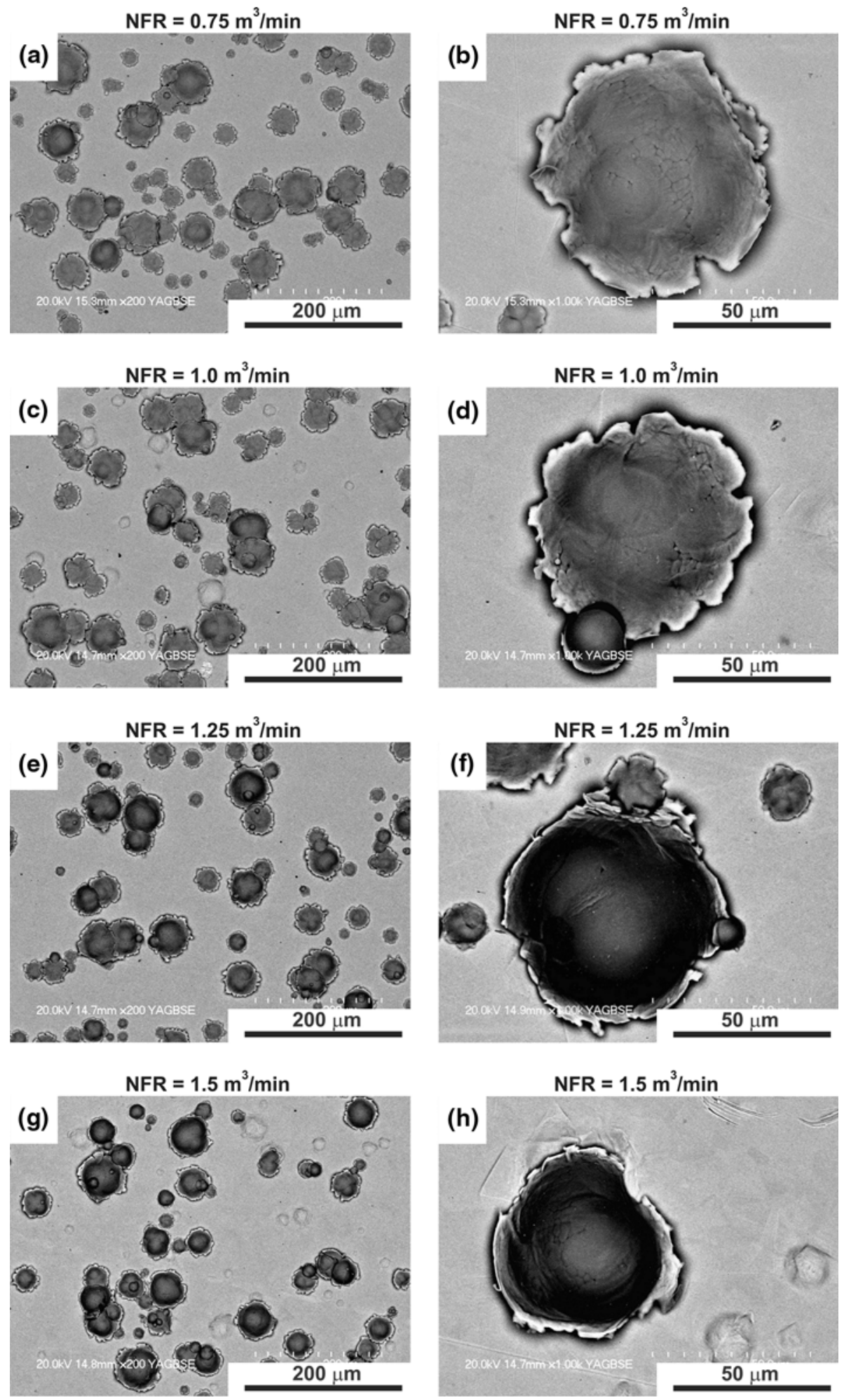

Fig. 12 Top views (a, c, e, g) and magnified views (b, d, f, h) of Ti-6Al-4V splats sprayed by high-pressure warm spray system at various nitrogen flow rates

should be considered as a minimal. Values of the porosity volume obtained with the use of high-pressure WS $(1.1 \%$ for coating formed at $1.0 \mathrm{~m}^{3} / \mathrm{min}$ ) are comparable to the coatings formed with the use of LPPS (0.7 to $1.8 \%$ ). However, since there is no data about oxygen content in formed coatings, thus a typical value for plasma atomized 
Ti-6Al-4V powder $(0.19 \%)$ was plotted in Fig. 11. Highpressure WS process seems be effective in terms of creating dense Ti-6Al-4V coatings with relatively low oxygen content in comparison to other kinetic spray process.

In thermal spray processes, the quality of coatings is influenced by both the temperature and velocity of sprayed particles. In WS process a coating is formed due to the intensive plastic deformation of particles impacting on a substrate at a temperature bellow the melting point of the spray material. To find out how the particles velocity and temperature affect plastic deformation of single particle a flattening ratio was determined.

Figure 12 shows backscattered SEM images of the topview of the deposited Ti-6Al-4V particles with the use of high-pressure WS system. For each spray condition, variously shaped and sized splats were found. Particles deposited with the lowest nitrogen flow rate (Fig. 12a and b) at higher particle temperature, seem to be more flattened than particles sprayed with higher nitrogen flow rates. In addition most of the impacted particles seem well bounded to the substrate. In the case of the particles sprayed with the lowest temperature, a number of them were rebounded from the surface leaving characteristic craters (Fig. 12g and h).

Deposition efficiency for the Ti-6Al-4V coatings formed with high-pressure WS varied in the range from almost 100 to about $72 \%$ for the coatings deposited from the lowest to the highest nitrogen flow rate, and these values are comparable to the values of deposition efficiency obtained with the use of CS (Ref 3, 26, 47). Wong et al. (Ref 47) showed that for deposition efficiency of Ti-6Al-4V particles an important parameter was powder processing performed before spraying process. They reported that deposition efficiency varied in the range from $93 \%$ for the as-received powder up to almost $100 \%$ for ball milled powder, which was explained by the reduction of the powder sphericity, and therefore easier mechanical anchorage of sprayed particles. Blose et al. (Ref 3) reported deposition efficiencies varied in the range from 86 to $66 \%$ as a function of powder morphology. From this point of view WS seems to be a relatively effective method in comparison with CS applied with the use of helium.

Figure 13 shows the mean values of the splats flattening ratio $(h / d)$, expressed by dividing splat height by its diameter, as a function of nitrogen flow rate and combustion pressure. To eliminate any powder size effect on the aspect ratio, particles of similar size were selected for each WS condition. Obtained results confirmed conclusions drawn from the SEM observations. Splats became more and more flattened while increase of WS temperature due to the thermal softening effect.

The flattening ratio appear to be in the range between 0.2 and 0.37 , depending on the process temperature, which was lower than values found for even more deformable materials deposited by $\mathrm{CS}$ such as $\mathrm{Al}(\mathrm{Ref} 50)$ or $\mathrm{Cu}$ (Ref 10, 51). Therefore, these data indicate that particles sprayed by WS were more heavily deformed without significant loss of deposition efficiency. Another important point was that particles applied by high-pressure WS were more flattened than particles deposited with using lower

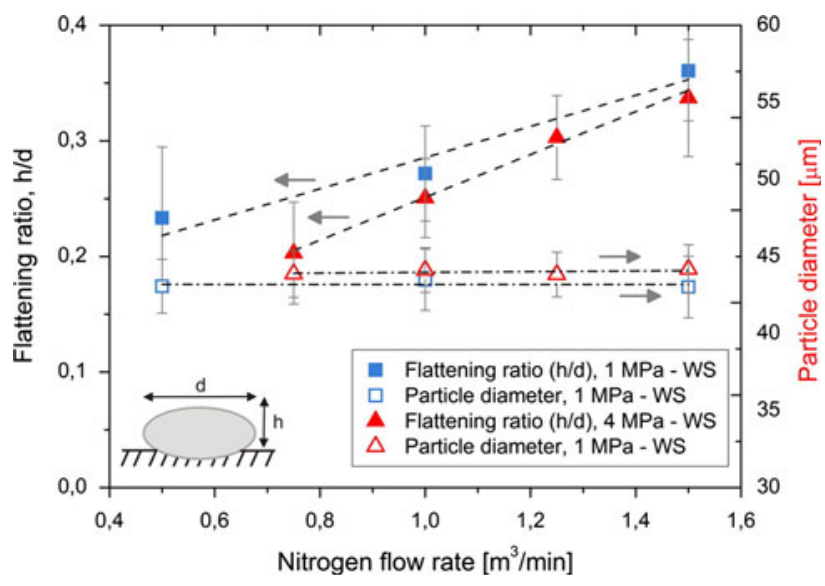

Fig. 13 Flattening ratio $(h / d)$ of splats sprayed by low- and highpressure warm spray system at various nitrogen flow rates

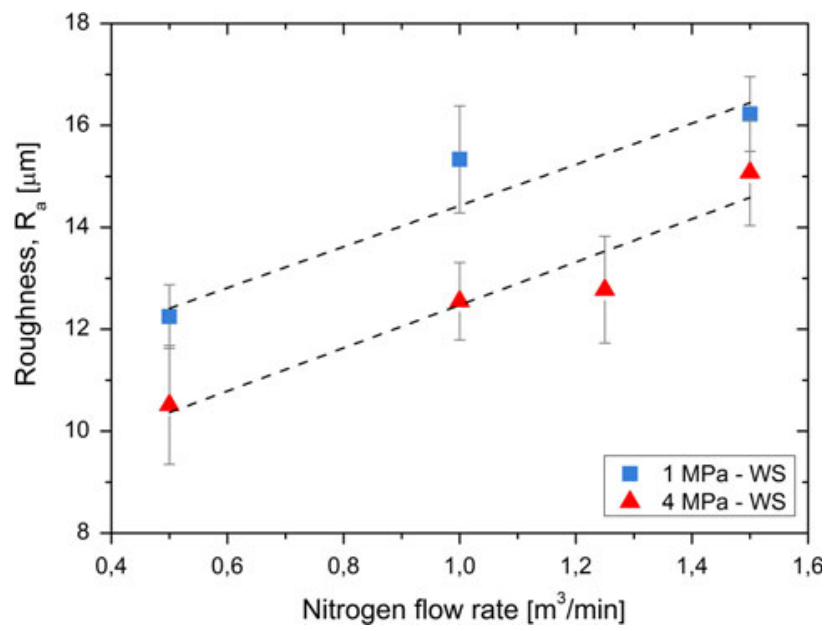

Fig. 14 Roughness parameter $\left(R_{\mathrm{a}}\right)$ of coatings formed by lowand high-pressure warm spray system at various nitrogen flow rate

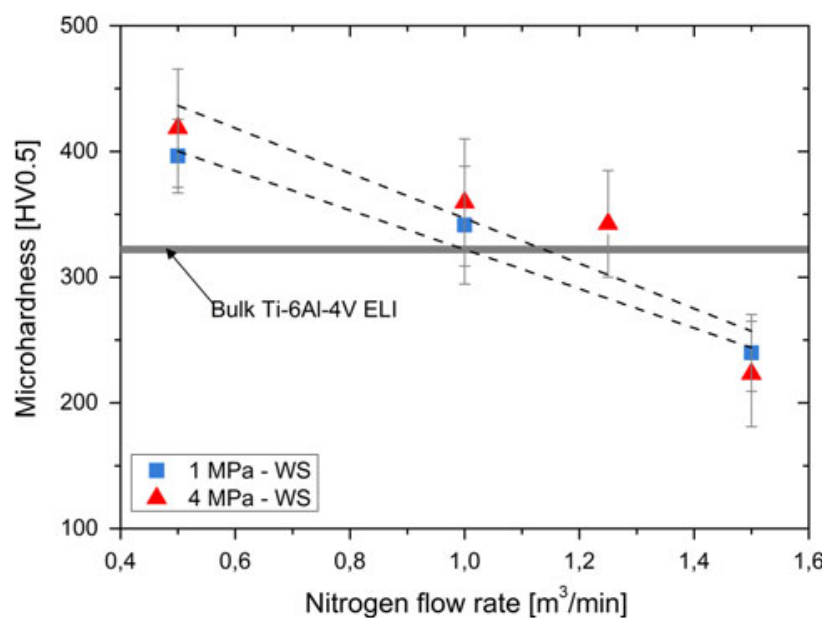

Fig. 15 Microhardness HV 0.5 of coatings sprayed by low- and high-pressure warm spray system as a function of nitrogen flow rate compared to the hardness of bulk material 

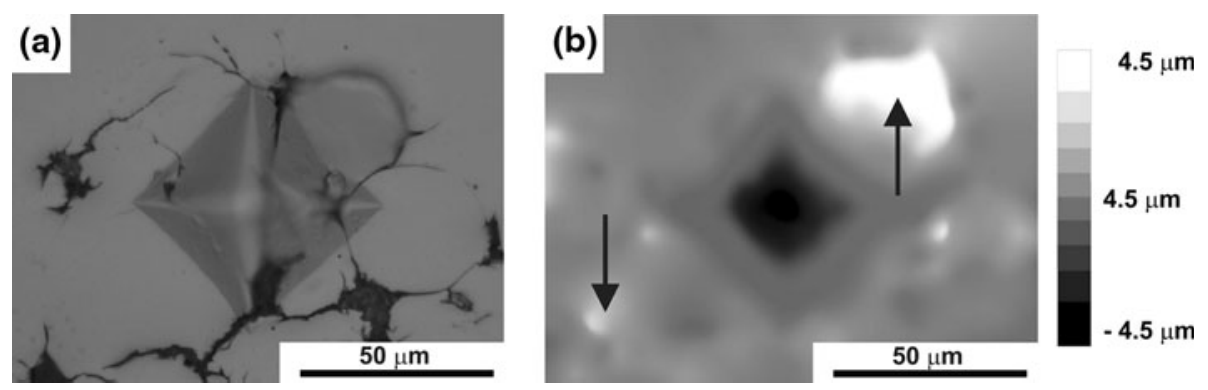

Fig. 16 Optical microscope images of cross-sectional area of Ti-6Al-4V coatings deposited at $1.5 \mathrm{~m}^{3} / \mathrm{min}$ after indentation by $\mathrm{Vickers}$ indenter, observed by typical optical microscope 2D mode (a) and with the use 3D mode (b); different gray level indicate elements of various heights

combustion pressure which is as expected from the differences in particles velocity. However, these differences are fairly low and close to the range of measurement error. Explanation of this effect is probably related to the limitations of the splats measurement method. It should be noted that measurements of both high and diameter of the splats were performed with the use of digital optical microscope for which reference level was at the surface of the base metal. Thus, portion of the particles which were embedded into base material were not taken into account in performed calculations. Since differences in particles velocity resulted in differences in depth of embedding, therefore final values of flattening ratio were affected by this phenomenon.

Because splats geometry is correlated with surface roughness, roughness measurement were conducted for WS coating samples as shown in Fig. 14. Obtained results show similar trend to that found for flattening ratio. The coatings sprayed at higher temperature result more flattened deposits and thereby smoother surface. In addition, it has been confirmed that coatings formed with help of high-pressure WS were smoother thanks higher particles velocity caused more flatten splats in contrast to lowpressure WS.

Finally, microhardness measurements were conducted for the WS coatings samples as shown in Fig. 15. In addition, the value of microhardness for bulk Ti-6Al-4V annealed for $2 \mathrm{~h}$ at $750{ }^{\circ} \mathrm{C}$ is shown in the graph. The results clearly indicate decrease in microhardness as a function of increase nitrogen flow rate, which results in decrease in the spray process temperature. The samples formed at the highest temperature (for the nitrogen flow rate of $0.5 \mathrm{~m}^{3} / \mathrm{min}$ ) exhibited the highest microhardness (419 HV 0.5 for high-pressure WS, 396 HV 0.5 for lowpressure WS) even higher than value of the bulk material (336 HV 0.5). With $0.5 \mathrm{~m}^{3} / \mathrm{min}$ in WS deposition, the spray particles were more heated and thermally softened than other WS conditions, resulted in larger deformation upon impact which caused work hardening effect. Increase in the microhardness with respect to as received material has been also found for titanium coatings deposited by CS (Ref 52, 53) and it was attributed to strain hardening phenomenon that occurred during deposition. Another phenomenon to increase microhardness was particles oxidation. When particle temperature is high, particles are significantly oxidized and thick oxides formed around particles (Fig. 9a and d). During the oxidation process, the high affinity of titanium to oxygen and the high solid solubility of oxygen into titanium (about $14.5 \%$ ) resulted in formation of the oxygen rich layer called $\alpha$-case because it is a continuous layer of oxygen stabilized $\alpha$ phase (Ref 1$)$. An increase in oxygen content strengthens the $\alpha$-case and therefore this phase is more hardened than the primary $\alpha$ phase.

On the other hand, particles cannot deform enough upon impact when particle temperature is low and result in porous microstructure. In addition, weak bonding strength between deposited splats can contribute to further reduction in microhardness. Figure 16 shows optical micrographs of a deformed area after indentation by a Vickers indenter visualized by the optical digital microscope. The different gray levels in Fig. 16(b) indicate elements of various heights in the field of view. Darkcolored elements are located below and light colored elements are located above reference level. The arrows in Fig. 16(b) indicate areas, where due to the indenter interaction; the weak bonded particles were detached from the other deposits. This effect showed reduced resistance of the material against indentation as manifest in decrease of microhardness. The other conclusion was that coating sprayed with the use of high-pressure WS exhibited slightly higher microhardness in contrast to lowpressure WS coatings. As explained previously, this effect is attributed to increase of particles velocity, which resulted in superior quality coatings both in terms of porosity and oxidation.

\section{Conclusions}

Ti-6Al-4V coatings were fabricated by the newly developed high-pressure WS equipment with various spray parameters. Based on the results presented above the following conclusions have been drown:

1. Modification of nozzle geometry and fuel injector (Ref 28) resulted in increase of the WS combustion pressure from 1 to $4 \mathrm{MPa}$ and increase in particles velocity close to $1000 \mathrm{~m} / \mathrm{s}$ was obtained. 
2. Due to the velocity enhancement Ti-6Al- $4 \mathrm{~V}$, coatings with better quality both in terms of porosity and oxygen content in contrast to low-pressure WS coatings were successfully formed. More specifically, at a porosity level of $1.1 \%$ oxygen content of $0.27 \%$ was achieved.

3. High-pressure WS formed even denser Ti-6Al-4V coatings in comparison to CS with the use helium as a propellant gas and comparable to coatings obtained by LPPS, however, with slightly higher level of oxygen content.

4. Both the barrel length and the spray distance were essential to the microstructure (porosity volume and oxides content) and mechanical properties of deposited coatings and the optimal values for Ti-6Al-4V coatings were identified experimentally.

\section{Acknowledgements}

The authors would like to thank Ms. A. Takenouchi for SEM observations of the feedstock powder. Mr. T. Hiraoka is thanked for operating the thermal spray equipment. In addition, appreciation goes to Mr. T. Mori for his valuable advice and help in operation of laboratory equipment.

Open Access This article is distributed under the terms of the Creative Commons Attribution License which permits any use, distribution, and reproduction in any medium, provided the original author(s) and the source are credited.

\section{References}

1. G. Lutjering and J.C. Williams, Titanium, 2nd ed., SpringerVerlag, Berlin, Haidelberg, 2003, 2007

2. R.H. Morgan, C.J. Sutcliffe, J. Pattison, M. Murphy, C. Gallagher, A. Papworth, P. Fox, and W. O'Neill, Cold Gas Dynamic Manufacturing: A New Approach to Near-Net Shape Metal Component Fabrication, Mat. Res. Soc. Symp. Proc., 2003, 758, p 73-84

3. R.E. Blose, B.H. Walker, R.M. Walker, and S.H. Froes, New Opportunities to Use Cold Spray Process for Applying Additive Features to Titanium Alloys, Met. Powder Rep., 2006, 61, p 30-37

4. D.A. Stewart, P.H. Shipway, and D.G. McCartney, Abrasive Wear Behaviour of Conventional and Nanocomposite HVOFSprayed WC-Co Coatings, Wear, 1999, 225-229, p 789-798

5. L. Ajdelsztajn, J.A. Picas, G.E. Kim, F.L. Bastian, J. Schoenung, and V. Provenzano, Oxidation Behavior of HVOF Sprayed Nanocrystalline NiCrAlY Powder, Mater. Sci. Eng. A, 2002, 338, p 33-43

6. K. Takeda, M. Ito, and S. Takeuchi, Properties of Coatings and Applications of Low Pressure Plasma Spray, Pure Appl. Chem., 1990, 62(9), p 1772-1782

7. T.S. Srivatsan and E.J. Lavernia, Use of Spray Techniques to Synthesize Particulate-Reinforced Metal-Matrix Composites, $J$. Mater. Sci., 1992, 27, p 5965-5981
8. A. Papyrin, Cold Spray Technology, Adv. Mater. Process., 2001, 159(9), p 49-51

9. F. Gärtner, T. Stoltenhoff, T. Schmidt, and H. Kreye, The Cold Spray Process and its Potential for Industrial Applications, $J$. Therm. Spray Technol., 2006, 15(2), p 223-232

10. H. Assadi, F. Gärtner, T. Stoltenhoff, and H. Kreye, Bonding Mechanism in Cold Gas Spraying, Acta Mater., 2003, 51, p 43794394

11. T. Schmidt, F. Gärtner, H. Assadi, and H. Kreye, Development of a Generalized Parameter Window for Cold Spray Deposition, Acta Mater., 2006, 54, p 729-742

12. C.J. Li, W.Y. Li, and H. Liao, Examination of the Critical Velocity for Deposition of Particles in Cold Spraying, J. Therm. Spray Technol., 2006, 15(2), p 212-222

13. M. Grujicic, J.R. Saylor, D.E. Beasley, W.S. DeRosset, and D. Helfritch, Computational Analysis of the Interfacial Bonding Between Feed-Powder Particles and the Substrate in the ColdGas Dynamic-Spray Process, Appl. Surf. Sci., 2003, 219(3-4), p 211-227

14. R. Huang and H. Fukanuma, Study of the Influence of Particle Velocity on Adhesive Strength of Cold Spray Deposits, J. Therm. Spray Technol., 2012, 21(3-4), p 541-549

15. D.L. Gilmore, R.C. Dykhuizen, R.A. Neiser, T.J. Roemer, and M.F. Smith, Particle Velocity and Deposition Efficiency in The Cold Spray Process, J. Therm. Spray Technol., 1999, 8(4), p 576582

16. V.K. Champagne, The Repair of Magnesium Rotorcraft Components by Cold Spray, J. Fail. Anal. Prev., 2008, 8, p 164-175

17. S. Kuroda, J. Kawakita, M. Watanabe, and H. Katanoda, Warm Spraying: A Novel Coating Process Based on High-Velocity Impact of Solid Particles, Sci. Technol. Adv. Mater., 2008, 9(3), p 1-17

18. J. Kawakita, H. Katanoda, M. Watanabe, K. Yokoyama, and S. Kuroda, Warm Spraying: An Improved Spray Process to Deposit Novel Coatings, Surf. Coat. Technol., 2008, 202(18), p 4369-4373

19. S. Kuroda, M. Watanabe, K.-H. Kim, and H. Katanoda, Current Status and Future Prospects of Warm Spray Technology, J. Therm. Spray Technol., 2011, 20(4), p 653-676

20. J. Kawakita, S. Kuroda, T. Fukushima, H. Katanoda, K. Matsuo, and H. Fukanuma, Dense Titanium Coatings by Modified HVOF Spraying, Surf. Coat. Technol., 2006, 201(3-4), p 1250-1255

21. K. Kim, S. Kuroda, M. Watanabe, R. Huang, H. Fukanuma, and H. Katanoda, Comparison of Oxidation and Microstructure of Warm-Sprayed and Cold-Sprayed Titanium Coatings, 2012, 21(34), p 550-560

22. M. Watanabe, C. Brauns, M. Komatsu, and S. Kuroda, Effect of Nitrogen Flow Rate on Mechanical Properties of Metallic Coatings by Warm Spray Deposition, Surf. Coat. Technol. (in press)

23. P. Chivavibul, M. Watanabe, S. Kuroda, J. Kawakita, M. Komatsu, K. Sato, and J. Kitamura, Effects of Particle Strength of Feedstock Powders on Properties of Warm-Sprayed WC-Co Coatings, J. Therm. Spray Technol., 2011, 20(5), p 1098-1109

24. P. Chivavibul, M. Watanabe, S. Kuroda, J. Kawakita, M. Komatsu, K. Sato, and J. Kitamura, Effect of Powder Characteristics on Properties of Warm-Sprayed WC-Co Coatings, $J$. Therm. Spray Technol., 2010, 19(1-2), p 81-88

25. Matthew and J. Donachie, Titanium: A Technical Guide, ASM International, Materials Park, 1998

26. Wong, A. Rezaeian, E. Irissou, J.-G. Legoux, and S. Yue, Cold Spray Characteristics of Commercially Pure Ti and Ti-6Al-4V, Adv. Mater. Res., 2010, 89-91, p 639-644

27. W.-Y. Li, Ch. Zhang, X. Guo, J. Xu, Ch.-J. Li, H. Liao, Ch. Coddet, and K.A. Khor, Ti and Ti-6Al-4V Coatings by Cold Spraying and, Microstructure Modification by Heat Treatment, Adv. Eng. Mater., 2007, 9(5), p 418-423

28. H. Katanoda, B. Sun, N. Ohno, H. Fukanuma, S. Kuroda, M. Watanabe, and O. Ohashi, Thermal Spray 2013: Design and Development of High-Pressure Warm Spray Gun, May 13-15, 2013 (Busan, Republic of Korea), ASM International, 2013

29. C.H. Chang and R.L. Moore, Numerical Simulation of Gas and Particle Flow in High-Velocity Oxygen-Fuel (HVOF) Torch, $J$. Therm. Spray Technol., 1995, 4(4), p 358-366

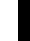


30. S. Gordon and B.J. McBride, Computer Program for Calculation of Complex Chemical Equilibrium Compositions and Applications, I, Analysis, NASA Reference Publications, Cleveland, 1994, p 1311

31. H. Katanoda, H. Morita, M. Komatsu, and S. Kuroda, Experimental and Numerical Evaluation of the Performance of Supersonic Two-Stage High-Velocity Oxy-Fuel Thermal Spray (Warm Spray) Gun, J. Therm. Sci., 2011, 20(1), p 88-92

32. C.K.W. Tam, J.A. Jackson, and J.M. Seiner, A Multiple-Scales Model of the Shock-Cell Structure of Imperfectly Expanded Supersonic Jets, J. Fluid Mech., 1985, 153, p 123-149

33. G. Kleinstein, Mixing in Turbulent Axially symmetric Free Jets, J. Spacecr., 1964, 1(4), p 403-408

34. P.O. Witze, Centerline Velocity Decay of Compressible Free Jets, AIAA J., 1974, 12(4), p 417-418

35. A.B. Bailey and J. Hiatt, Sphere Drag Coefficient for a Broad Range of Mach and Reynolds Numbers, AIAA J., 1972, 10(11), p $1436-1440$

36. Y.P. Wan, V. Prasad, G.-X. Wang, S. Sampath, and J.R. Fincke, Model and Powder Particle Heating, Melting, Resolidification, and Evaporation in Plasma Spraying Processes, J. Heat Transf., 1999, 121(3), p 691-699

37. H. Katanoda, M. Fukuhara, and N. Iino, Numerical Study of Combination Parameters for Particle Impact Velocity and Temperature in Cold Spray, J. Therm. Spray Technol., 2007, 16(5-6), p 627-633

38. T. Stoltenhoff, H. Kreye, and H.J. Richter, An Analysis of the Cold Spray Process and its Coatings, J. Therm. Spray Technol., 2002, 11(4), p 542-550

39. T. Schmidt, F. Gaertner, and H. Kreye, New Developments in Cold Spray Based on Higher Gas and Particle Temperatures, $J$. Therm. Spray Technol., 2006, 15(4), p 488-494

40. X. Yang and S. Eidelman, Numerical Analysis of a High-Velocity Oxygen-Fuel Thermal Spray System, J. Therm. Spray Technol., 1996, 5(2), p 175-184

41. K. Sakaki and Y. Shimizu, Effect of the Increase in the Entrance Convergent Section Length of the Gun Nozzle on the HighVelocity Oxygen Fuel and Cold Spray Process, J. Therm. Spray Technol., 2001, 10(3), p 487-496
42. W.-Ch. Lih, S.H. Yang, C.Y. Su, S.C. Huang, I.C. Hsu, and M.S. Leu, Effects of Process Parameters on Molten Particle Speed and Surface Temperature and the Properties of $\mathrm{HVOF} \mathrm{CrCrNiCr}$ Coatings, Surf. Coat. Technol., 2000, 133-134, p 54-60

43. J. Pattison, S. Celotto, A. Khan, and W. O'Neill, Standoff Distance and Bow Shock Phenomena in the Cold Spray Process, Surf. Coat. Technol., 2008, 202, p 1443-1454

44. K. Kim, M. Watanabe, J. Kawakita, and S. Kuroda, Effects of Temperature of In-Flight Particles on Bonding and Microstructure in Warm-Sprayed Titanium Deposits, J. Therm. Spray Technol., 2009, 18(3), p 392-400

45. M. Fukumoto, M. Mashiko, M. Yamada, and E. Yamaguchi, Deposition Behaviour of Copper Fine Particles onto Flat Substrate Surface in Cold Spraying, J. Therm. Spray Technol., 2010, 19(1-2), p 89-94

46. K. Kim and S. Kuroda, Amorphous Oxide Film Formed by Dynamic Oxidation During Kinetic Spraying of Titanium at High Temperature and its Role in Subsequent Coating Formation, Scripta Mater., 2010, 63, p 215-218

47. W. Wong, E. Irissou, J.G. Legoux, P. Vo, and S. Yue, Powder Processing and Coating Heat Treatment on Cold Sprayed Ti-6Al4V Alloy, Mater. Sci. Forum, 2012, 706-709, p 258-263

48. H.R. Salimijazi, T.W. Coyle, and J. Mostaghimi, Vacuum Plasma Spraying: A New Concept for Manufacturing Ti-6Al-4V Structures, JOM, 2006, 90, p 50-56

49. K. Balani, A. Agarwal, S. Seal, and J. Karthikeyan, Transmission Electron Microscopy of Cold Sprayed 1100 Aluminum Coating, Scripta Mater., 2005, 53, p 845-850

50. K. Kang, S. Yoon, Y. Ji, and Ch. Lee, Oxidation Dependency of Critical Velocity for Aluminium Feedstock Deposition in Kinetic Spraying Process, Mater. Sci. Eng. A, 2008, 486, p 300-307

51. W.-Y. Li, H. Liao, Ch.-J. Li b, G. Li c, Ch. Coddet, and X. Wang, On High Velocity Impact of Micro-Sized Metallic Particles in Cold Spraying, Appl. Surf. Sci., 2006, 253, p 2852-2862

52. S. Gulizia, A. Trentin, S. Vezzù, S. Rech, P. King, M. Jahedi, and M. Guagliano, Characterisation of Cold Spray Titanium Coatings, Mater. Sci. Forum, 2010, 654-656, p 898-901

53. S.H. Zahiri, Ch.I. Antonio, and M. Jahedi, Elimination of Porosity in Directly Fabricated Titanium Via Cold Gas Dynamic Spraying, J. Mater. Process. Technol., 2009, 209, p $922-929$ 